NASA NGL OS-002-069

(NASA-CR-158457) CORE FORMATION, EVOLUTION, N79-21696 AND CONVECTION: A GROPBYSICAL HODEL

(California Inst. of. Tech.) $59 \mathrm{p}$ , HC A04/AE A01

CSCI. 086

G3plas $\quad$ Unclas

CORE FORMATION, EVOLUTTON, AND CONVECTION;

A GEOPHYSICAL MODEI

By

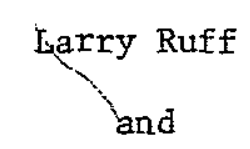

Don L. Ànderson
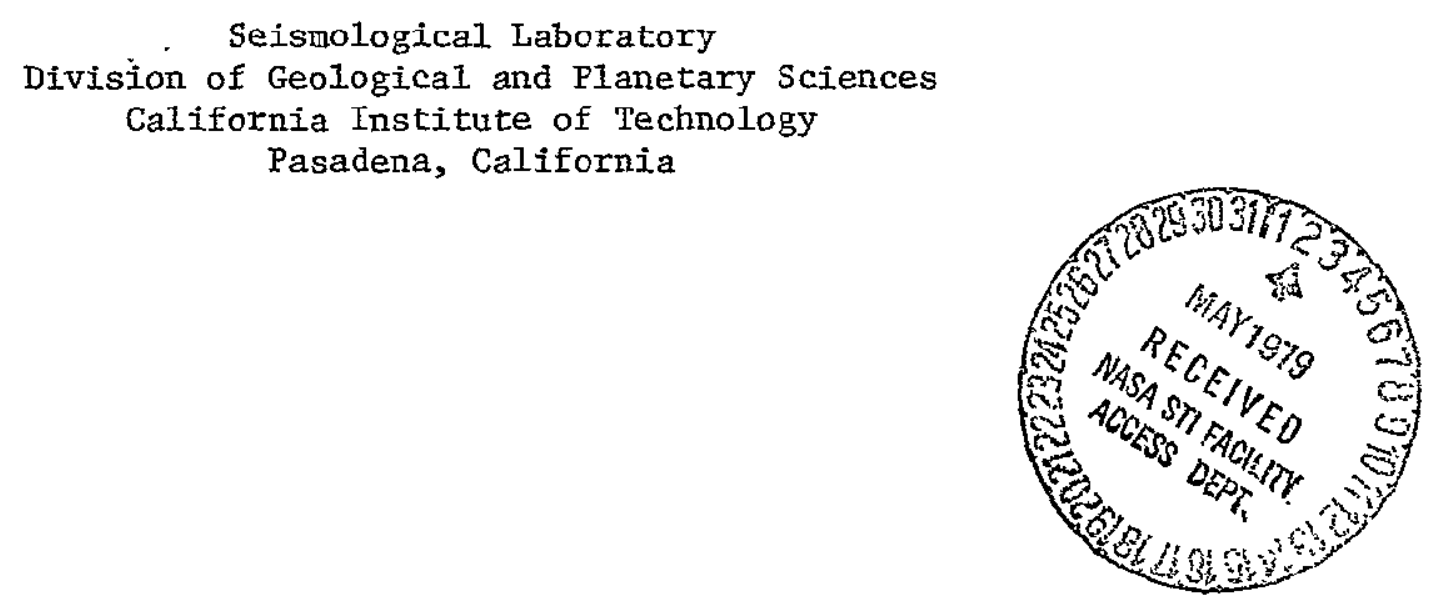

Contribution Number 3096, Division of Geological and Planetary Sciences, California Institute of Technology, Pasadena, California 91125 
ABSTRACT

We propose a model for the formation and evolution of the Earth's core which provides an adequate energy source for maintaining the geodynamo. A modified inhomogeneous accretion model is proposed which leads to initial iron and refractory enrichment at the center of the planet. The probable heat source for melting of the core is the decay of ${ }^{26} \mathrm{Al}$. The refractory material is emplaced irregularly in the lowermost mantle with uranium and thorium serving as.a long lived heat source. Fluid motions in the core are driven by the differential heating from above and the resulting cyclonic motions may be the source of the geodynamo. 
INTRODUCTION

The problems of the origin of the Earth's magnetic field and the evolution of the Earth's interior have usually been treated separately. Ultimately, a model for the accretion and evolution of the Earth will need to satisfy the physical and geochemical constraints and will also need to provide the necessary conditions for the existence and behavior of the magnetic field. The model we present is primarily concerned with the core and is a simple model in the sense that we follow the events that would occur as the natural consequences of inhomogeneous accretion. This approach is rather successful in that it is consistent with seismological and geochemical data and it also provides necessary conditions for causing fluid motions within the core which might be sufficient for maintaining the Earth's magnetic field. This last point is not certain, however, as the fluid motions are dependent on some physical properties of the core which are poorly determined. Also, the argument for generation of the magnetic field is not a complete dynamical treatment.

It should be noted that at this time, amid the controversy of the existence of ${ }^{40} \mathrm{~K}$ in the core, there is no model for the formation and evolution of the core which provides for the necessary fluid motions and energy demand of the magnetic field, particularly in view of the possibility that the outer core is thermally or compositionally stratified. Our model predicts a stratified core but can still cause fluid motions in this case. The basic outline of this paper is the following: First we briefly discuss the Earth's magnetic field, dynamo models and the requirements for 
the maintenance of the field. Next, we describe the inhomogeneous accretion hypothesis and present a model for the formation of the core and lowermost mantle. Finally, the flufd motions implied by the model and related dynamo processes are discussed.

\subsection{Geodynamo}

The Earth's magnetic fleld is still largely unexplained in terms of physical processes within the Earth. The magnitude and geologic history of the magnetic field require electric currents flowing in a highly conductive fluid core (E1sasser, 1947; Bullard, 1949; Jacobs 1975). There have been many efforts to find a dynamo process appropriate for the Earth, that is, fluid motions within the outer core which regenerate the main magnetic field.

Due to the mathematical difficulties in treating the complete dynamical system, dynamo models derived for the terrestrial and astrophysical magnetic fields are generally kinematic models. The kinematic approach neglects the equations of fluid motion and heat transfer and considers just the hydromagnetic equation,

$$
\frac{\partial \underline{B}}{\partial t}=\bar{\nabla} \cdot x(\underline{V} \times \underline{B})+n \underline{\nabla^{2}} \underline{B}
$$

where $\underline{B}$ is the magnetic field, $\underline{V}$ is the fluid velocity, and $\eta$ is the magnetic diffusivity. A particular velocity field is prescribed along with an inftial magnetic fleld and a regenerative solution to the above equation is then soụght. This approach has yielded several successful models (see Levy 1976 for a review). The successful velocity fields found vary from large scale nearly axisymmetric motions (e. g. Moffatt, 1973, G. 0. Roberts, 1972, and P. H. Roberts, 1971) to small scale turbulence with a particular statistical nature (Krause, Rädler, Steenbeck, see translation by $P$. H. Roberts and $M$. Stix, 1971; Moffatt, 1970). Cyclonic fluid motions with a radial component of velocity have appeared in several dynamo models (Parker, 1955, 
Levy, 1972) and in the limit of small length scale can be likened to the turbulent dynamo model. The cyclonic model also has the capability of producing a self-reversing dynamo (Parker 1969, 1971, Levy, 1972), an important observed feature of the Earth's magnetic field. Although other velocity fields can produce a dynamo, the cyclonic model is particularly pertinent to our core model.

Kinematic models can thus describe velocity fields necessary for a dynamo, but they do not indicate the source of filuid motions. These are usually assumed to result from thermal convection within the core. Efforts toward a dynamic treatment including thermal convection have produced a few results, notably the "convective rolls" dynamo of Busse (1973) and, relevant to our core model, the Rossby wave dynamo of Gilman (1969) as extended by Braginsky and Roberts (1975).

\subsection{Geophysical Problems of the Magnetic Field}

One" strong constraint on the geodynamo is that adequate energy be supplied to maintain the magnetic fleld. Due to ohmic losses, energy must be supplied to the magnetic fleld through the velocity field. Since the magnetic field has existed at nearly the same intensity for at least 2.7 billion years (McElhinney, et al, 1968, Jacobs, 1975), and the decay time for the fundamental mode of the magnetic field has been estimated at about 10,000 years (Cox, 1972), there has seemingly been a near constant energy supply over geologic time.

In a recent paper, Gubbins (1976) reviewed the energy requirements of the magnetic field and provided lower and upper bounds on the energy supply. The upper bound is of order $10^{20} \mathrm{erg} / \mathrm{sec}$ which is the observed surface heat flux, and the lower bound is $2 \times 10^{17} \mathrm{erg} / \mathrm{sec}$ by consideration 
of conduction and electric currents. This requires an energy source acting over geologic time of considerable size. The precessional dynamo of large scale motions has been eliminated on the basis of energy constraints (Rochester et al. 1975 : Loper, 1975, Rochester, 1977). Latent heat released from the supposed growth of the inner core is marginal as an energy supply, producing motions restricted to near the inner core. (Verhoogen, 1973, Gubbins, 1976). The secular variations of the magnetic field require substantial f1uid motions in the outermost core (Elsasser, 1946; Backus, 1968; Kahle et al.., 1967; Rikitake, 1967).

The only other potential energy sources are radiogenic heating and, possibly,gravitational mechanical stirring (Urey, 1952, Braginsky, 1964 , Gubbins, 1976, Loper, 1977). It was in the context of searching for an energy source that ${ }^{40} \mathrm{~K}$ was suggested to be in the outer core (Lewis, 1971). This suggestion is rather arbitrary and is not consistent with any known differentiation process. Since the initial suggestion, some workers have tried to demonstrate that under certain conditions potassium would partition into a metalifc phase (i.e. the Fe core) from a silicate phase (Hall and Murthy, 19̈71, Goette1, 1972)'. Other experimental studies have indicated that little or no potassium enters the metallic phase (Oversby and Ringwood, 1972, Seitz and Kushiro, 1974, Ganguly and Kennedy, 1977). The observational evidence argues against significant potassium in the metallic phase at low pressures. Bukowinski (1976) calculated that potassium would take on the characteristics of a transition metal at high pressures, but this does not imply that potassium will be selectively partitioned into the core (Ringwood, 1977). This issue is still controversial, but aside from whether or not potassium would partition into the metallic phase is the problem of the amount required. Murthy and Hall (1972) require three-fourths of the potassium within the Earth to be segregated into the metallic core. To partition that amount of potassium into the core is inconsistent with any 
accretion and evolution model for the Earth including the homogeneous accretion model (Ringwood, 1975). The question of potassium in the core is coupled to the question of sulfur in the core. There are other candidates for the lighter alloying element (Ringwood, 1977). Therefore, since the initial assumption is rather arbitrary and because this assumption appears inconsistent with the geochemistry of the Earth, the problem of the energy source is still open.

To fill this gap, the idea of a mechanically stirred core has been revitalized. The basic idea is that the inner core has grown continuously over the age of the Earth by precipitating $\mathrm{Fe}$ and $\mathrm{Ni}$, excluding the lighter element from the inner core. This process releases a lighter fraction near the inner core boundary which then causes fluid motions. If the inner core has grown with time and if there is a compositional difference between the inner and outer core, this process may well occur. However, it is not clear that it would be important fox the magnetic field, particularly if the core is stratified. The quantitative calculation of the potential energy release (Loper 1977) assumed an adiabatic temperature gradient throughout the core over geologic time, and this assumption conflicts with many recent results including those of Gubbins (1976). Any stability within the, core, even if only in the outermost part, seriously affects the gravitational energy. available for fluid motions, and, as will be discussed later, precipitation of Fe from the outer core implies a compositionally stratified core. Equation of state fits to the outer core have suggested that it is either non-adiabatic or chemically inhomogeneous, or both (Bullen, 1969;-Butler and Anderson, 19.78). This conclusion has implications for the dynamo mechanism, particularly for a dynamo model that uses large-scale motions throughout the outer core.

Therefore, at present there is no consensus on the most. fundamental problem of a sufficient energy source much less any detail of the fluid motions. 
At this point, we will preview the results of our core model which are relevant to the above problem of an energy source. The final configuration of the model predicts material enriched in $U$ and $T h$ around the core, the radioactive isotopes producing up to $10^{20} \mathrm{ergs} / \mathrm{sec}$ which represents the upper constraint given by Gubbins. With this large amount of available energy, why have $U$ and Th not been seriously considered previously? In the early development of dynamo theory, Bullard (1949) and Elsasser (1950) did suggest $\ddot{U}$ and $T h$ as candidate radiogenic heat sources. However, at that time it did not seem possible for $U$ and $T h$ to be associated with the core (Urey, 1952), and the idea fell into disfavor. Since that time, however, there has been considerable progress in the geochemical and dynamical aspects of the accretion and early history of the Earth. In particular, for the present discussion, the modeling of the condensation sequence and the fall of Allende meteorite in 1969 have been essential in the development of a quantitative inhomogeneous accretion model.

\section{THE GEOPHYSICAI MODEL}

We will only briefly summarize the general aspects of the inhomogeneous. accretion model as there is an extensive literature concerning the model in relation to the Earth, meteorites, and the entire solar system ( see Clark, Turekian and Grossman, 1972, Grossman and Larimer, 1974, Anderson, 1972, 1973, Turekian and Clark, 1969, Larimer and Anders, 1967., Larimer, 1967.). The essential idea is the Earth accreted material during the condensation of the solar nebula, as opposed to homogeneous accretion in which accretion is delayed until after the completion of condensation. By accreting during condensation, the initial structure of the Earth would be influenced by the condensation sequence. The condensation sequence as determined by theoretical calculations of Grossman is shown in Figure 2, calculated at the supposed appropriate pressure. One prediction from this 
sequence is that most of the metallic iron would condense before most of the silicates. The volatiles would condense and accrete toward the end of the accretion process. Therefore, the metallic Fe core is present from the beginning, avoiding many of the difficulties faced by core formation in homogeneous accretion models (e.g. Ringwood, 1972, Anderson and Hanks, 1972). This general consideration along with the gross structure of the solar system have given support to this idea, but perhaps the more convincing evidence comes from the detailed geochemistry of meteorites. This model has been successful in predicting major and trace element chemistry and some minerology of meteorites. In particular, the Allende meteorite contains "white inclusions", which have a rather unique chemistry and mineralogy. It is now generally accepted (Mason and Martin, 1975, Lee, Papanastassiou and Wasserburg, 1977) that these white inclusions represent the initial refractory condensate.

We use the following varlant of the inhomogeneous accretion hypothesis. Planets accrete as the nebula cools and the accreting material has the composition of the solids that are in equilibrium with the nebula at that temperature plus the more refractory material that has condensed earlier and escaped accretion. The mean composition of the Earth therefore becomes less refractory with time and with radius. After dissipation of the nebula the Earth continues to slowly accrete material that has condensed in its vicinity and the more volatile material that condensed further out in the solar system. It is not proposed that all of the refractories and iron are accreted before the silicates. There is always unaccreted material available for interaction with the gas. Iron, for example, is accreted as metal at the early stages but reacts with the silicates to form the ferromagnesium silicates that are accreted later. Likewise, Ca, AI, U and Th are available for incorporation into the later condensates but they are enriched in the early condensates. 
A "pure" inhomogeneous accretion model is not essential to the arguments in this paper. It is only required that the iron and refractories start to accrete before the majority of the silicates which form the present mantle. The viability of the inhomogeneous accretion hypothesis, for our purposes, depends on the relative time scales of nebula cooling and accretion in the early stages of condensation. If cooling is slow relative to accretion rates then the iron and refractories will form the initial nuclei of the planets. Alternatively, cooling can be rapid if temperatures in the vicinity of the Earth did not drop far into the olivine-pyroxene stability fleld before dissipation of the nebula. In this case, the majority of the mantle would be added by material perturbed into Earth orbit from cooler parts of the nebula. The earliest condensates also have more time for accretion and possibly experience more viscous drag. Thus, there are several arguments supporting the view that the proto-Earth was refractory and became more volatile rich with time.

One of the early criticisms of inhomogeneous accretion for the Earth was that it did not seem possible to melt the initial metallic core after It was accreted and buried. Attempts to do this by the thermal history of accretion (Hanks and Anderson, 1969, Clark, Turekian and Grossman, 1972) were unsatisfactory. Anderson and Hanks (1972) pointed out that the condensation sequence predicts a refractory $\mathrm{Ca}$, Al rich initial condensate before the condensation of metallic iron (see Figure 2). Therefore, there would be $\mathrm{Ca}$, Al rich silicates accreting with the metallic iron and both the theoretical calculations and measurements of the Allende inclusions show this initial condensate to be enriched in uranium and thorium as well as other heavy metals (Figure 2). Therefore, the inhomogeneous accretion model also predicts a long-lived heat source within the initial core. However, it will be shown that the short-lived nuclide ${ }^{26} \mathrm{~A} 1$ can dominate the early thermal history and be responsible for melting of the core. 


\subsection{The Inhomogeneous Core Model}

If the inhomogeneous accretion model is interpreted Iiterally one would expect to accrete all the refractory material in a small protocore, prior to the accretion of metallic iron. It is more likely that the iron and refractories accreted together as suggested by the work of . Matsul and Mizutani (1977) and Neukem (1968). Therefore, we allow an initial configuration varying from "pure" to "distributed" as depicted in Figure 3. Regardless of the details of the original configuration, the amount of refractory material can be estimated by assuming that $\mathrm{Fe}$ and the refractory material were accreted in accordance to their relative solar system abundance, 1.e., the Earth received its full complement of $\mathrm{Ca}$, $\mathrm{Al}$ silicates relative to iron. To cover a range of possibilities, we also consider a "one-tenth" model, where we assume that only one-tenth of the refractory material was accreted with or within the iron. The refractory component near the center is not the entire refractory compliment of the Earth. In the later stages of accretion the refractories continue to accrete in more nearly chondritic abundances. The Earth, then is enriched in refractories by about the amount that it. is enriched in iron, relative to cosmic abundances. By considering the complete and one-tenth relative abundances with the pure and distributed geometries, we have covered a broad range of accretion histories thereby testing the stability of the model with regard to the particular accretional history of the Earth.

- The amount of refractory material accreted is calculated by considering Al and $\mathrm{Ca}$, the two major elements which would be completely condensed before Fe. Table 1 shows the amount of $\mathrm{Ca}$ and $\mathrm{Al}$ oxides that are accreted with the iron for the complete and one-tenth models. The mass of Fe in the core Is estimated by taking a density distribution close to Earth mode1 BI (Jordan and Anderson, 1974) and subtracting 15\% due to other elements within the present core (Ringwood, 1966, Anderson, 1977). The amount of Ca and AI 
(as oxides) is then determined by their abundance relative to Fe (e.g. Ross and Aller, 1976)

To obtain the total mass of the refractory material, we have used the major element composition of Type A Allende inclusions which are considered the best examples of early refractory condensates (Grossman, 1975). The range of compositions of the major oxides in the Type A inclusions are shown in Table 2 along with theoretical calculations at two temperatures. . The good agreement merely restates the conclusion of Grossman and others.

The composition we have chosen to use for the refractory material in the Earth is indicated in Table 2. The total mass of refractory material can then be calculated from the accreted mass of either $\mathrm{CaO}$ or $\mathrm{Al}_{2} \mathrm{O}_{3}$ given in Table 1 . The results for both of these oxides are shown in Table 3 for complete and one-tenth accretion. Thus we now have the mass of refractory material accreted with the core for either complete or one-tenth accretion. It reprèsents about $10 \%$ of the mass of the core.

We now consider the present day distribution of $\mathrm{Ca}$ and $\mathrm{Al}$ oxides in the mantle. Taking estimates of the composition of the crust and upper mantle (Wyllie, 1971) we calculate about $10^{26} \mathrm{~g}$ for both $\mathrm{CaO}$ and $\mathrm{Al}_{2} \mathrm{O}_{3}$, assuming the entire mantle has abundances similar to the upper mantle. This will be an upper bound if the upper mantle is a differentiate of the lower mantle. This is 30 to $50 \%$ less than the amount estimated to be in the Earth on the basis of the size of the core and the inhomogeneous accretion hypothesis. Although these calculations are crude they are consistent with the hypothesis (Anderson, 1975) that the lowermost mantle can be enriched in refractories.

\section{$2.2 \mathrm{U}, \mathrm{Th}$ and Heat Production}

From the predicted condensation sequence (Figure 2), we would expect the initial condensates to be enriched in the rare earths and other 
trace refractories such as $U$ and $T h$. The enrichment factor for reffractories between Allende inclusions and $\mathrm{Cl}$ chondrites is about 20 (wänke ẹt aI., 1974; Mason and Martin, 1975, Ganapathy and Grossman, 1976). The only elements of these groups that we consider in detall are $U$ and Th due to their significance as long-lived heat sources. It is also possible that short-lived isotopes such as ${ }^{i 244} \mathrm{Pu}$ could contribute to the early thermal history. The concentrations of U and Th are listed in Table 4. The value of $U$ is the mean concentration from nine coarse-grained Allende inclusions (Ganapathy and Grossman, 1976) and is consistent with other results (Wänke et al., 1974). The concentration of Th is obtained by assuming the cosmic abundance ratio of $T h / U \sim 4$. Some evidence suggests that this ratio is higher, perhaps 6-8 (e.g. Mason and Martin, 1975). A Th/U of elght would increase heat production by about $50 \%$ but since we are considering order of magnitude quantities, this factor is ignored. We also ignore the time dependence of heat generation since the half-lives of $U$ and $T h$ are equal to and longer than the age of the Earth.

It should be noticed that the estimates for heat production of the order $10^{19}-10^{20}$ ergs/sec are at the upper limit of the energy demand of the magnetic field as discussed in part one, and these estimates are more than two orders of magnitude higher than the minimum energy required. Therefore, there is more than sufficient energy within or near the core as a simple consequence of inhomogeneous accretion.

The Earth's crust is enriched in $U$ relative to the average abundance for the whole Earth and there is a gradation from high to low concentration in rocks from the upper crust to the upper mantle. The total amount of U in the early condensate is of the same order as the total amount estimated for the Earth (see for example, Gast, 1972). A comparable additional amount will be brought in by accretion of the mantle consistent with our version of 
inhomogeneous accretion: Using the $\mathrm{Ca}$, Al oxides in the mantle as a guide to the distribution of other refractories in the mantle, we estimate that there could be of the order $10^{19}$ gms. of $U$ concentrated around the core, sufficient to provide $10^{19}$ ergs/sec heat energy.

\subsection{Initial and Final Geometry}

As previously discussed, we will consider two inftial configurations of the refractory material within the core. The two geometries of pure and distributed accretion are shown in Figure $3 a, 3 b$ along with simplified density distributions for each. The distributed geometry'represents the case where individual planetesmials of $\mathrm{Fe}$ and refractory material were accreted together throughout the core.

Since we know that the present core does not contain a silicate protocore (e.g. Birch, 1968; Jacobs, 1975) within it and that the refractory silicates would be gravitationally unstable in an Fe core, the refractory material. would be emplaced in the lowermost mantle at the core-mantle boundary. Furthermore, this emplacement will be a very rapid event, particularly as the core becomes more fluid. Thus, the refractory matertal will be distributed irregularly as depicted in Figure $3 c$.

The gravitational potential energy difference between the inttial and final configurations is estimated by using the density profiles in Figure 3. We assume (i) a sharp boundary between the core and mantle (1i) the equations of state of Fe and the refractorles compensate each other so that there is no change of volume (radius) and (iii) the value of $\rho=8 \mathrm{gm} / \mathrm{cm}^{3}$ for the refractory protocore, a rather arbitrary extrapolation from the lower mantle.

We estimate the potential energy release to be $\sim 10^{37 \pm 1}$ ergs. Using the physical properties for Fe listed in Table $5,10^{37}$ ergs could 
either melt the entire core, or raise the overall temperature $500 \mathrm{~K}$ and melt half the core. As potential energy is released, the associated temperature rise would increase the rate of potential energy release due to a lowering of viscosity or the melting of the core. Thus, there is a cascading effect that leads eventually to the emplacement of the refractories into the highly disturbed lowermost mantle. As a consequence of this event, the lowermost mantle could have lateral variations of different size scales. We are mainly concerned with a size scale of $1,000 \mathrm{k} \neq l o m e t e r s$ for considering the geodynamo: The seismological evidence for lateral variations in the lowermost mantle will be discussed later.

\subsection{Early Thermal History}

To estimate the time scale of the segregation event we need to specify the initial temperature and then determine the time scáles of radiogenic heating and gravitational rising of the refractory material. Calculated initial temperature profiles of the accreted Earth (e.g., Hanks and Anderson, 1969) are not fully appropriate as they have considered the material accreted as a thin shell. Recent work on the detalls of planetesmial impacts (O'Keefe and Ahrens, 1976) have shown that a larger. portion of energy can be trapped within the planet. Also, the effect of an early atmosphere has not been evaluated. Consequently, we will consider an initial, temperature for the Fe core based on the accretion temperature and adiabatic heating which will be a lower bound as accretional heating is neglected which could be important in the outermost core.

Although the condensation temperature of $\mathrm{Fe}$ is about $1400 \mathrm{~K}$, we will use an accretion temperature of $1200 \mathrm{~K}$-as. this is the temperature at which most of the Mg silicates would be condensed. This provides a lower bound on the temperature of the accreted core. The adiabatic heating is on the 
oṛder of a fẹ hundred degrees (Jacobs, 1975); we use a value of $300 \mathrm{~K}$. Thus, the Initial temperature of the inhomogeneously accreted core is greater than $1500 \mathrm{~K}$ : This is indicated in Figure 4 along with some estimates of the Fe melting curve and the Fe-S eutectic. Although we do not require that sulfur be the light element in the core, the Fe+S eutectic is shown to demonstrate the importance of the lighter element in lowering the initial melting point. Other candidates for the light element should also form a eutectic system with Fe (Ringwood, 1975).

There is a large uncertainty in how much the core must be heated to initiate melting. The two Fe melting curves in.Fig.4 represent a range of proposed values, and the time of melting depends' on whether the eutectic curve is appropriate or not. Instead of making the most conservative estimate of the temperature rise required to inftiate melting of the core (i.e., taking the initial temperature of $1500 \mathrm{~K}$ and using the Higgins and Kennedy melting curve), we will consider the various heat sources and the associated temperature rise in the core within two bilition years (the time constraint to provide a fluid core from paleomagnetism, McElhinny et al. 1968).

The contribution to heating from the long lived radiogens $U$ and $T h$ varies from possibly useful to insignificant depending on which value of heat production is used, $10^{19}$ or $10^{20} \mathrm{ergs} / \mathrm{sec}$. Using the heat capacity listed in Table 5.and assuming that the heat is retained in the core, Heat Production $\approx 10^{20} \mathrm{ergs} / \mathrm{sec} \rightarrow 500 \mathrm{~K}$ Temperature rise in $2 \mathrm{~b} . \mathrm{y}$. " $" 10^{19} \mathrm{ergs} / \mathrm{sec} \rightarrow 50 \mathrm{~K} \quad$ " " " A $500 \mathrm{~K}$ temperature increase could be important, however $\mathrm{U}$ and Th cannot melt the core in sufficient time. Using the heat of fusion from Table 5 and a heat production of $10^{20}$ ergs/sec., the time required to melt the entire core would be $\imath 2.2$ billion years. Figure 4 shows that more than 
a $500 \mathrm{~K}$ temperature rise would be required to start melting. Therefore, $\mathrm{U}$ and Th cannot heat the core and then melt it within $2 \mathrm{~b} \cdot \mathrm{y}$.

The role of short-lived radiogenic heat sources in the planets and meteorites has been discussed to a certain extent (e.g. Urey, 1955; Fish, Goles and Anders, 1960) $\cdot{ }^{26} \mathrm{Al}$ is the most important isotope in view of its heat production capability. However, with a half life of $0.72 \mathrm{~m} \cdot \mathrm{y} \cdot,{ }^{26} \mathrm{Al}$ would be a significant heat source for a limited time after nucleosynthesis. We can quantify this, as there is now evidence from the Allende white inclusions that ${ }^{26}$ Al was present with an initial abundance ratio ${ }^{26} \mathrm{~A} 1 /^{27} \mathrm{Al}=5 \times 10^{-5}$ (Lee, Papanastassiou, and Wasserburg, 1977). Using this abundance ratio and the refractory mode1 composition in Table 2 , there would have been a total heat production from ${ }^{26} \dot{A}$ of $1.2 \times 10^{12}$ ergs per gram of refractory material. For the average model of $\sim 2 \times 10^{26}$ gms. refractories, this would be a total heat production of $2 \times 10^{38}$ ergs. This is enough energy to raise the core temperature by more than $10,000 \mathrm{~K}$. Of the other short Iived. radiogens, ${ }^{244} \mathrm{Pu}$ and ${ }^{236} \mathrm{U}$ are the most important. The half-lives and heat production of these isotopes are 1 isted in Table 6 . There is some evidence for ${ }^{244} \mathrm{Pu}$ in the Allende inclusions (Shirck, 1974) and the concentration of ${ }^{244} \mathrm{Pu}$ in Table 5 is based on that data. The concentration of ${ }^{236} \mathrm{U}$ wàs estimated by Urey (1955) to be the same as ${ }^{238_{U}}$, and we have taken one tenth that value. If the total heat production from ${ }^{244} \mathrm{Pu}$ and ${ }^{236} \mathrm{U}$ was distributed throughout the core, it would raise the overall temperature by only $10 \mathrm{~K}$.

We can conclude then, that of the known short-lived isotopes, ${ }^{244} \mathrm{Pu}$ and ${ }^{236} \mathrm{U}$ are not important, whereas ${ }^{26} \mathrm{~A} 1$ could raise the overall core temperature by more than $1,000 \mathrm{~K}$ and melt it even if the proto-core accreted $3 \mathrm{~m} . \mathrm{y}$. after Allende. Given the assumption of inhomogeneous accretion, it seems likely that ${ }^{26} \mathrm{Al}$ is responsible for melting the core. 
It should be noted, however, that ${ }^{26} \mathrm{AI}$ is not required to melt the core. Another energy source is the potential energy release upon redistribution of mass in the core. This energy release will proceed before the core is molten if we regard the core as a viscous fluid. We will assume an upper bound on viscosity and find the characteristic time for a planetesmial of refractory material to move $1,000 \mathrm{~km}$. radially by a Stokes calculation (Lamb, 1932), thereby indicating the time scale for release of potential energy into heat energy. If we take a viscosity of $10^{20}$ poise, then the characteristic time for a planetesmial with a size scale of $i \mathrm{~km}$. is 1 billion years, and if the viscosity is $10^{15}$ poise the characteristic time for a 10 meter fragment of refractories is $100 \mathrm{~m} \cdot \mathrm{y}$. These time scales are less than the $2 \cdot \mathrm{b} \cdot \mathrm{y}$. time constraint.

In suminary, we find two significant heat sources which could either independently or acting together in some combination raise the core temperature $1,000 \mathrm{~K}$ or. more and be responsible for the inftial melting. 'The decay of ${ }^{26} \mathrm{AI}$ is the largest heat source and could accomplish the above if.the Earth was accreted within 3 m.y. after the formation of the Allende inclusions, assuming these to be representative of early condensates in our nebula. We propose that ${ }^{26} \mathrm{Al}$ was important, at least for providing a partially melted core. The other significant hẹat source is the potential energy release associated with the rising refractories, and our calculation for an assumed upper limit of the available energy shows this heat source capable of melting at least some fraction of the core. Even if there is no significant heating of the core due to elther long or short lived radiogens, the refractory material rising through the viscous solid core would release the potential energy on a time scale of $1 \mathrm{~b} \cdot \mathrm{y}$. or less. 
Therefore, we conclude that the inhomogeneous accretion model for the core is capable of producing at least a partially molten core within. 2 b.y. after accretion. The refractory material would be emplaced into the lowermost mantle and we would expect an irregular distribution.

\subsection{Physical Properties of Refractories}

After the emplacement of the refractories in the lowermost mantle, there remains the question of whether or not this material wili, stay there over geological time. If the refractory material is lighter than the normal mantle around $1 t$, then it would rise through the mantle. Therefore, we need to estimate the relative densities of normal mantle and refractory material and we do this by using shock wave results.

The component phases relevant to the model compositions are compiled in Table 7 with their inferred shock wave densities at $1.2 \mathrm{Mbar}$, a pressure corresponding to $\sim 250 \mathrm{~km}$. above the core-mantle boundary. The uncertainty in shock temperatures $(2,000-4,000 \mathrm{~K}$, Jeanloz, personal communication) roughly corresponds to the uncertainty in the geotherm at the core-mantle boundary (Jacobs, 1975). We are primarily concerned with relative densities between two, compositions and we assume that any difference between the dynamic and static densities applies to both model compositions in approximately the same proportion.

We have used a pyrolite composition (Ringwood, 1972) for "normal" mantle. The pyrolite model has been developed to fit both the geochemical and geophysical constraints of the upper mantle. The pyrolite and refractory models are listed in Table 8 . Calculated composite densities are given in Table 9 for different mineral assemblages. The densities in the lowermost mantle are estimated as $5.4 \pm 0.1 \mathrm{gm} / \mathrm{cm}^{3}$ for the refractory material and $5.3 \pm 0.1 \mathrm{gm} / \mathrm{cm}^{3}$ for normal mantle. 
It is concluded that the refractory material is gravitationally stable in the lowermost mantle within the errors of the presently available technique and data.

Though not crucial in terms of affecting the evolution of the core, we also estimate the difference in bulk sound velocity between normal mantle and the refractories. This physical property is important as a seismological effect to test the model. The oxides and $\mathrm{CaSiO}_{3}$ (perovskite structure) and their seismic parameter $\phi$ are given in Table 10 . Using the additivity of $\phi$ (Anderson, 1969), the pyrolite model gives $\phi=60$ which agrees with the extrapolated lower mantle $\phi$ (Anderson and Jordan, 1970). This corresponds to a bulk sound velocity of $7.7 \mathrm{~km} / \mathrm{sec}$ for normal mantle. For the refractory material, with an oxide mineralogy, the bulk' sound 'velocity is $7.35 \mathrm{~km} / \mathrm{sec}$ which $1 \mathrm{~s} \sim 5 \%$ 1ower than normal mantle. With $\mathrm{Ca}$ in the perovskite structure the bulk sound velocity is $7.1 \mathrm{~km} / \mathrm{sec}, \sim 8 \%$ lower than normal mantle. Thus, from this cursory treatment; we would predict a difference in bulk sound velocity of around $5 \%$ betweèn normal and refractory lowermost mantle. Observational seismology related to' this is discussed later.

\subsection{Inner Core and the Light Element}

- Tẉo features of the core which are associated with core formation and evolution are the solid inner core and the required light element in the outer core.

There are two 'processes that could cause a solid inner core;

(i) the core did not become completely molten during the segregation event and the solid. material coalesced into the solid inner core, (ii) freezing of the inner core due to gradual cooling. It is possible that both of these processes have occurred, (1.e., there was an initial 
inner core due to incomplete melting and over geologic time there has been some addition of solid precipitate). The detalls are obviously dependent on the early thermal history, in particular the ${ }^{26} \mathrm{AI}$ abundance and the redistribution of potential energy. The second process is controlled by the thermal gradient and the melting gradient. The Inner core is presently $5 \%$ of the mass of the core and it could either have grown or eroded with time, depending on the balance between heating and cooling.

$\because$

Equations of state, seismic velocity, and shock wave analyses have indicated that the Fe-NI outer core contains $\sim 10 \%$ of a lighter element (e.g., Birch, 1952, 1964; Knopoff and MacDonald, 1960; Anderson, Sammis and Jordan, 1972). The candidates that have been given the most attention are $0, \mathrm{Mg} . \mathrm{Si}$, and $\mathrm{S}$. In view of our model, sulfur could only be added as CaS, a refractory, or as FeS, a late stage condensate trapped in the mantle. The amount of caS avallable is likely to be trivial. Fes in the mantle would tend to drain to the interior because of its low melting point and high density. Ringwood (1977) has recently discussed the core in. terms of a $\mathrm{Fe} 0-\mathrm{Fe}$ solution approximating $\mathrm{Fe}_{2} \mathrm{O}$ in composition. Some fraction, presumably small, of the refractories may be dissolved in the core.

After the core segregation event, the fluld outer core would be left in an adiabatic state. Whether or not the core remains thermally stable depends on the distribution of heat sources and the state of the mantle. If all the $U$ and Th is removed with the refractorles to the lowermost mantle then the only energy sources in the core are a growing inner core and further gravitational separation in the outer core. Gubbins (1976) has indicated that inner core latent. heat is not capable of maintaining an adiabatic gradient throughout the core (See Figure 5 for this gradient and a range of core adiabatic 
gradients). The characteristic conduction time $T$ is given by $T \sim L^{2} / K$ where $L$ is the radial length scale and $K$ is the thermometric conduction. Using $L \sim 1,000 \mathrm{~km}$ and $k \sim 10^{-1} \mathrm{cgs}, T \sim 3$ billion years. Therefore, we would not expect an isothermal core even in the absence of heat sources.

Two other possibilities for generating a supermadiabatic gradient somewhere within the core both pertain to the outermost core; solubility of some $U$, Th in the core and a sudden cooling from the mantle. Assuming an internal heating appropriate for $10 \%$ of the initial $U$ and Th, the steady state gradient (Figure 5) is subadiabatic except perhaps in the outermost core. The other gradient shown in Figure 5 is a transient effect due to a sudden decrease of temperature in the lowermost mantle. Since the characteristic conduction time of the mantie is much Ionger. than that of the core, this cooling could only be caused by downward convection of "cold plumes" within the mantle in the sense of McKenzie et al. (1974), or the upward removal of hot material as thermal (Morgan, 1971) or chemical plumes (Anderson, 1975). These processes involving . whole mantle motions might occur periodically but we do not consider them . important for causing a superdiabatic gradient for maintenance of the magnetic “ifield.

In considering the gradients plotted in Figure 5, it seems possible that the core could be adiabatic in some parts but probably not throughout, therefore causing thermal stability against whole core convection.

The subject of compositional stratification of the fluid outer core has been considered by Usselman (1975). He assumed the fluid to be at the iiquidus composition of the Fe-FeS system at core conditions. The details of the calculation do not apply if the light element in the core is not sulfur. However, if the core is a eutectic system; a general 
conclusion is that for a core temperature between the liquidus and the eutectic, the core is probably compositionaily stratified. This can be seen in Figure 6 for a range of core adiabatic gradients. Only if the temperațures are well above, the liquidus throughout would one expect a chemically homogeneous core. The fact that the inner core is'below the liquidus, argues, for a compositionally stratified core if the outer core is close to adiabatic. To be compositionally homogeneous the core would be sub-adiabatic. Therefore it is possible that the core is either. compositionally or thermally stable thus resisting whole core convection, as required by the gravitational stirring mechanism which stipulates a sub-liquidus adiabatic core. This conclusion restricts possible radial fluid motions.

\subsection{Summary of Geophysical Model}

Before discussing the fluid motions in the core we sumarize the main points of the present model:

The early condensates, $\mathrm{Ca}$ and $\mathrm{Al}$ rich silicates, heavy refractory metals, and Fe accreted to form the protocore. The early thermal history is likely to be dominated by ${ }^{26} \mathrm{Al}$ which, for the average refractory model, can produce enough heat to raise the core temperatures by $1,000 \mathrm{~K}$ and melt it even if the Earth accreted $3 \mathrm{~m} . \mathrm{y}$. after Allende. In the absence of ${ }^{26} \mathrm{Al}$, potential energy release could still melt some fraction of the core.

Melting of the core results in unmixing and the emplacement of refractory material (including $U$, Th and possibly ${ }^{26} \mathrm{AI}$ ) into the lowermost mantle. The lowermost mantle should be laterally inhomogeneous from a scale of perhaps 1 to $1,000 \mathrm{~km}$. Calculations of the physical 
properties of the refractory material and normal mantle demonstrate that the refractories will be gravitationally stable in the lowermost mantle, but will have a velocity difference of a few percent. The lowermost mantle should, therefore, be inhomogeneous and a scatterer of seismic energy, which is observed.

Depending upon the avallable heat energy, the Fe core could have been either completely or partially molten at the time of unmixing. Therefore, the present solid Inner core could be remnant solid Fe (or $\mathrm{Fe}-\mathrm{Ni}$ ) from the segregation event, or it may have grown through geologic time from the preclpitation of the solid phase from the fluid core.

Even. if as much as one-tenth the initial $U$ and Th is present in the fluid' core, an adiabatic temperature gradient is not maintained throughout the entire core. However, the core could be adiabatic in some parts. There is also a possibility of compositional stratification. As a consequence, parts of or all of the core may be stable against convection.

There is some seismic data relating to the state of the lowermost mantle. There are two regions of the mantle which show significant scatter in their properties; the upper mantle and the lowermost mantle. There is a variety of evidence of anomalous lower mantle properties, both large scale lateral variations and short period scattering (e.g., Julian and Sengupta, 1973; Sacks and Beach, 1974; Husebye, King and Haddon, 1976; Doornbos and Husebye, 1972, Haddon and Cleary, 1973). 
There have been some attempts to look at regional differences in the lowermost mantle (Phinney and Cathles, 1969; Mondt, 1977; Wright and Lyons, 1975). The general conclusion has been that there are regional differences, but these results are not yet definitive. For the purposes of determining the size' and length scale of some particular. lateräl variation in the lowermost mantle, a detailed high resolution study of a portion of the lowermost mantle is required.

We will examine brief1y the interaction of whol'e mantle convection with the lowermost mantle. If there is whole mantle convection, then material in the lowermost mantle will be transported upward. The factors influencing this are; the stability of the refractories (i.e., their density, viscosity and Grüneisen parameter relative to normal mantle), the style of convection, and boundary layer effects. We propose distributed refractories as a cause of fluid motions in the core. They could also serve to drive convection in the mantle and may also actively participate in the convection and thereby be removed. For example $\mathrm{CaO}, \mathrm{AI}_{2} \mathrm{O}_{3}, \mathrm{U}$ and Th are enriched in the crust and it is usually assumed that they have been efficiently removed from the mantle, or at least the upper mantle.

In " the following section, the basic assumption is that at least some refractories have been retained in the lowermost mantle throughout geologic time.

\section{Fluid Motions and the Geodynamo.}

We have shown that $U$ and Th can provide enough heat energy to maintain the Earth's magnetic field against dissipative losses, These elements have the advantage over ${ }^{40} \mathrm{~K}$ of providing a uniform heat source over 
geological time. Fulfilling the energy demand of the geodynamo does not, however, guarantee that the dynamo process will occur. Since the basic mechanism of the geodynamo is fluid motions within the core, $\because$ a complete model for the core should provide sufficient fluid motions for generation of the magnetic field. Though it is of ten stated that almost any "sufficiently complicated" three dimensional fluid fliow will cause a dynamo, the explicit demonstration of a regenerative dynamo has been done for only a few flow geometries as mentionéd earlier. In view of this, we first consider the basic character of the fluid motions, and then relate this to specific dynamo models appropriate to our model.

The dynamics of a rotating thermally stable fluid with laterally varying surface heating has been extensively studied both theoretically and experimentally due to its relevance to atmospheric motions (see Hide and Mason 1974; Fowlis and Hide, 1965, Phillips, 1963). The geometry usually considered in these studies is a rotating cylindrical system with heating in the middle and cooling on the outside or vice versa. The geometry of the system for the Earth is shown in Figure 7 where the heating and cooling is also indicated. Lateral heat transport in the mantle is negligible compared to the core, because the mantle thermal conductivity is an order of magnitude lower, and the viscosity orders of magnitude higher than the values for the core. Therefore, the lateral heat transport takes place in the core where fluid motions redistribute the heat. Although any, fluid with lateral surface heating will have convecțion (e.g., Landau and Lifshitz; 1959), we need to check if convection dominates conduction as the mode of heat transfer. 
The non-dimensional parameter which compares the effects of advection to conduction of heat is the Rayleigh number $\mathrm{Ra}$, where $\mathrm{Ra} \gg 1$ indicates that convection of heat dominates. $\mathrm{Ra}$ is given by:

$$
\operatorname{Ra} \sim \frac{\alpha F L_{o}{ }^{4} g}{\rho c_{p} \kappa^{2} v}
$$

where $\dot{L}_{o}$ is the largest characteristic length. With the physical parameters given in Table 5 and the flux $F$ given by $1 / 10$ of the $U$ and Th of the initial condensates distributed over one-tenth of the surface of the core then $\operatorname{Ra} v 10^{23} \gg 1$. Therefore, conduction can be neglected and for the length scales considered the Taylor number Ta $\sim 10^{8}>1$, indicating that the interior flow is inviscid. The effect of rotation is measured by the Rossby number Ro, and for our system the external Rossby number Ro $\sim 10^{-7} \ll 1$. Therefore, rotation is important and the quasi-geostrophic approximation is valid so that there is an azimuthal "thermal wind" rotating around the heat source (see also, Holton, 1972), i.e., a cyclonic motion. This type of fluid flow is shown in Figure 8a. The symmetric fluid flow is subject to wavelike instabilities in the azimuthal flow lines, as depicted in Figure $8 \mathrm{~b}^{\circ}$, which correspond to the lateral transport of hot and cold fronts. These baroclinic instabilities will occur for the dimensionless parameter $B<1$, where

$$
B^{1 / 2} \backsim \frac{w_{B} D}{f L_{0}}
$$

$\omega_{B}$ is the Brunt frequency and $D$ is the characteristic vertical scale, For our purposes, a more useful criterion of stability is to use the horizontal length scale of the baroclinically unstable waves $I_{B}$ as 
indicated in Figure $8 \mathrm{~b}$ where

$$
L_{B} \sim B^{1 / 2} I_{O}
$$

Thus, if $\mathrm{B}^{1 / 2} \sim 1$ or $\mathrm{B}^{1 / 2}>1$, the azimuthal-flow is stable, while if $B^{1 / 2}<I$ the preferred length scale of the system will be smaller than $I_{0}$. The above relation can be rewritten as

$$
\mathrm{I}_{B} \sim\left(\alpha \mathrm{gT}^{*}\right)^{I / 2} \frac{\mathrm{D}}{\mathrm{F}}
$$

where $T^{*}=\Gamma-\frac{d T}{d Z}$ is the difference between the adiabatic gradient and the actual temperature gradient. As the actual gradient approaches the adiabatic gradient, $\mathrm{T} * 0$ so that $\mathrm{I}_{\mathrm{B}}$ tends to zero. That is, the fluid flow breaks up into small eddies until a new balance with the viscous term is reached.

Although we do not know $T^{*}$ exactly, from our earlier thermal considerations we expect that the core is sub-adiabatic but not isothermal. The characteristic depth scale $\dot{\mathrm{D}}$ will also depend upon the vertical stability of the fluid. If the core is adiabatic, then the fluid motions could extend throughout the core. A core gradient less than adiabatic will confine the motions to the outermost core. Given the uncertainty in the temperature gradients, we cannot provide a definite answer to even an order of magnitude, but it is possible to determine an upper bound on $\mathrm{L}_{B}$ by taking both $\mathrm{T}^{*}$ and $\mathrm{D}$ as their largest values which are, $T * \sim \Gamma \sim 10^{-5} \mathrm{deg} / \mathrm{cm}$ and $\mathrm{D} \sim 10^{8} \mathrm{~cm}$. This gives $\mathrm{L}_{B}$ $\sim 1,000 \mathrm{~km} \sim I_{0}$, and since an isothermal core, and vertical scale length of $1,000 \mathrm{~km}$ are limit conditions, we are virtually assured that $I_{B}<$ $\mathrm{L}_{\mathrm{o}} \sim 1,000 \mathrm{~km}$ and, therefore, the style of fluid motions ts that of a baroclinically unstable azimuthal flow which can break up irito small cyclonic and anticylonic eddies of scale $\dot{L}_{B}$. For example, with 
$\mathrm{T}^{*}=0.5 \times 10^{-6} \mathrm{deg} / \mathrm{cm}$ and $\mathrm{D} \sim 1.0 \mathrm{~km}, \mathrm{~L}_{\mathrm{B}} \sim 10 \mathrm{~km}$, indicating the strong effect of vertical stability upon $D$. This regime of flow with a relatively small length scale is shown in Figure $8 \mathrm{c}$ and is referred to as the irregular regime from experimental work (Fowlis and Hịde, 1974).

Our treatment of fluid motions has been rather curșory. This is justified by the large uncertainties of the pertinent physical parameters. The main point is to establish the style of fluid motions in the absence of Lorentz forces and this simple scaling analysis indicates that the basic flow will be a baroclinically unstable azimuthal flow breaking up into small eddies for a strong vertical stability.

If the Lorentz force does not alter the basic fluid motions, we could then argue that the cyclonic motions produced are those required by the kinematic dynamo models of either large scale cyclonic cells (Parker, 1955; Levy, i972), or in the limit of small scale eddies the $\alpha \omega$ and $\alpha^{2}$ dynamos from mean field electrodynamics (e.g., Moffatt, 1972; Steinbeck, Radiler and Krause, 1971). This is not necessary, however, since work-exists that considers directly the dynamo effects of baroclinically unstable waves. Gilman (1969) introducè a Rossby wave dynamo with particular application to the Sun and found regenerative, dynamo action although his treatment was not. completely rigorous. One difficulty encountered, particularly if the core is stably stratified, thereby limiting the vertical scale height, is the regenerative capability of the vertical motions. The horizontal motions will cause a large toroidal field, but some vertical component is needed to regenerate the poloidal field. Thus, work such as that of Braginsky and Roberts (1975) is important as they found the regenerative effects of baroclinic waves are, in fact, concentrated at the "critical level" where the wave and thermal' wind velocities are equal. 
Although the argument is not complete, it appears that the fluid motions expected in the outermost core are those of a dynamo for which regenerative effects could be confined to a small vertical scale.

Even if the character of fluid motions is appropriate for a regenerative dynamo process and there is sufficient heat energy available to the core, there still remains the question of converting the heat energy to magnetic field energy. This is made easier by Moffatt's (1972) analysis. He concluded that the magnetic energy density would be equal to, or greater than, the kinetic energy density. Therefore, we will consider just the conversion of heat energy to mechanical energy in the absence of the magnetic field. As the efficiency of this conversion is strongly dependent upon the depth of fluid motions, we will, instead choose a minimum desired efficiency and then find the corresponding depth scale by considering a cycle of heat transfer as 1.) cooling along the core-mantle boundary by $\Delta T, 2$.$) adiabatic sinking to a depth with temperature change \Delta \mathrm{T}$, and then 3.) isothermal heating of the rising fluid. If we use the ideal thermodynamic efficiency' (Bullard and Gellman, 1954; Metchnik et al., 1974), for the core and require a minimum efficiency (0.1\%) so that $10^{20} \mathrm{erg} / \mathrm{sec}$ heat energy is converted to $10^{17}$ ergs $/ \mathrm{sec}$ mechanical energy, the depth scales for adiabatic gradients of $10^{-5}-10^{-6} \mathrm{deg} / \mathrm{cm}$ are $0.3-$ $3.0 \mathrm{~km}$. Therefore, the fluid motions extend to a depth of order $1 \mathrm{~km}$ and more likely to $10 \mathrm{~km}$ or more.

This section on the fluid motions and geodynamo is mostly qualitative. To provide a rigorous connection requires specifying the important physical parameters $\left(\mathrm{e} . \mathrm{g}, \mathrm{T}^{*}\right)$ and solving the complete dynamical problem. It is not possible to do either of the above problems, now, although in the future better estimates of $\mathrm{T}^{*}$ and other 
parameters may be provided and dynamical treatments may be feasible. The main emphasis of this section has been to at least qualitatively demonstrate that though the fluid motions from a differentially heated core may occur at a length scale ranging from 1 to $1000 \mathrm{~km}$, they correspond to types of motion used in various dynamo models, from the Rossby wave dynamo for large scale motions to $\alpha \omega$ and $\alpha^{2}$ dynamos if the motions are small scale.

To conclude this section, we should note that although we have attributed the geodynamo to fluid motions caused by differentià surface heating, other motions of different size and time scalès within the core are not excluded. In particular, if the core is stable and the inner core has grown throughout geologic time; then either suspendë $\mathrm{Fe}$ precipitate or lighter fluid at the inner core boundary would collect until the stability is exceeded causing overturning in the core (see Loper and Roberts, 1978). This effect could play a role in the puzziling behavior of the frequency of magnetic field reversals (i.e., the "quiet periods"), which displays a time scale on the order of $100 \mathrm{~m} \cdot \mathrm{y}$. (McElhinny, 1971; Reid, 1972; Stewart and Irving, 1973). Thus, our view is that core motions may be composed of steady motions in the outermost core which provide the main magnetic field with possibly other motions in the interior such as an occasional overturn. An interesting feature of a geodynamo generated by laterally varying mantle heat sources is that field irregularities may persist over. time and space as the irregular heat sources are locked in the mantle. 


\section{Summary}

A geophysical model for the formation and evolution of the core and lowermost mantle is proposed which follows from the inhomogeneous accretion hypothesis. It is proposed that ${ }^{26} \mathrm{~A} 1$ dominates the early thermal history. One of the important consequences of the model is that long lived radioactive heat sources are distributed irregularly in the lowermost mantle and drive the fluid motions in the core which may be responsible for the geodynamo. Seismological evidence indirectly supports this model. The anomalous lower mantle velocity gradient suggests chemical inhomogeneity and/or a high thermal gradient. The evidence for lateral variations suggests a varying composition. We have shown that the refractory composition is stable in the lowermost mantle. Although uncertainties in the model parameters and physical parameters of the core do not allow a unique prediction of the state of the core, the questions of stability of the core and origin of the inner core are cleariy seen in context of the model.

In presenting the model, we have considered the known important physical and geochemical constraints, including the existence of the magnetic fieid, and conclude that an inhomogeneous accretion model is at least compatible with all factors. A new driving mechanism, differential heating from above, is proposed to sustain the dynamo.

\section{Acknowledgments}

We profited from discussions with Andrew Ingersoll and Raymond Hide. Also, F. Busse and A. H. Cook provided helpful comments. This research was supported by NASA \#NGL05-002-069. Contribution Number 3096, Division of Geological and Planetary Sciences, California Institute of Technology, Pasadena, California 91125. 
References

Ahrens, T., Jackson, I. and Jeanloz, R.. (I977), Proc. Lunar Sci. Conf. 8 th , 3437-3455.

Anderson, D. (1969), J. Geophys. Res. 74, 3857-3864.

Anderson, D. (1972), Comments Earth Sci.: Geophys. 2, 93-98.

Anderson, D. (1973), The Moon $\underline{8}, 33-57$.

Anderson, D. (1975), Geol. Soc. Am. Bu11., 86, 1593-1600.

Anderson, D. and Jordan, T. (1970), Phys. Earth P1anet. Interiors $\underline{3}$, 23-35.

Anderson, D. and Hanks, T. (1972), Nature, 237, 387-388.

Anderšon, D., Sammis, C., Jordan, T. (1972), ịn: E. Robertson, ed., The Nature of the Solid Earth (McGraw-Hill)

Backus, G. (1968), Phil. Trans. R. Soc. A 263, 239.

Birch; F. (1952), J. Geophys. Res. 57, 227.

Birch, F. (1964), J. Geophys. Res. 69, 4377.

Booker, J. (1969), Proc. Roy. Soc. A $309,27-40$.

Braginskii, S. (1964), Geomag. Aeron. IV, 572 .

Braginskii, S. and Roberts, P. (1975), Proc. R. Soc. A 347, 125-140.

Bukowinski, M. (1976), Geophys. Res. Letters 3, 491-493.

Bullard, E. (1949a), Proc. R. Soc. A 197, 433.

Bullard, E. (1949b), Proc. R. Soc. A 199, $413^{\circ}$

Bullard, E. and Gellman, H. (1954), Phil. Trans. R. Soc. A 247, 213.

Bullen, K. (1969), Geophys. J. 18, 7.3.

Bullen, K. and Haddon, R. (1967), Phys. Earth Planet. Interiors 1 , 1 . Busse, F. (1973), J. Fluid Mech. 57, 529.

Butler, R. and Anderson, D. (1978), Phys. Earth Planet. Interiors in press. 
Carslaw; H. and Jaeger, J. (1959), Conduction of Heat in Solids, 2nd ed. (Oxford University Press. London).

Cathles, L. (1975), The Viscosity of the Earth's Mantle (Princeton University Press, Princeton, N.J.)

Clark, s. (1966) ed., Handbook Phys. Constants, Mem. 97, Geo1. Soc. Am. (N.

Clark, S., Turekian, K. and Grossman, L. (1972), in: E. Robertson, ed., ..

The Nature of the Solid Earth. (McGraw-Hil1).

Cox, A: (1972), Int. Conf. Core-Mantle Interface, Trans. Am. Geophy. Un. $53,61 \dot{3}$.

Davies, G. (1974), Geophys. J. 38, 479-503.

Doornbos, D. and Husebye, E. (1972), Phys. Earth Planet. Int. 5 , 387.

Elsașser, W. (1946), Phys. Rev. 70, 202.

Elsasser, W. (1947), Phys. Rev. 72, 821.

Elsasser, W. (1950), Rev. Mod. Phys. $\underline{22}, 1$.

Fish, R., Goles, G. and Anders, E. (1960), Astrophys. J. 132, 243.

Flaser, F. and Birch, $\dot{F}$. (1973), J. Geophys. Res. 78, 6101.

Fowlis, W. 'and Hide, R. (1965), J. Atmos. Sci. 26, 100.

Frazer, M. (1973), Geophys. J. 34, 193-201.

Ganapathy, R. and Grossman, L.' (1976), Earth Planet. 'Sci. Lett. 31, 386-392.

Ganguly, J.' and Kennedy, G. (1977), Earth Planet. Sci: Letters 35, $411-420$

Gast, P. (1972), in: E. Robertson ed., The Nature of the Solid Earth, (MçGraw-Hi11, New York).

Gilman, P. (1969), Solar Phys. 8, 316-330.

Gilman, P. (1969), Solar Phys. 9, 3-18.

Goette1, K. (1972), Phys. Earth Planet. Int. $\underline{6}$, 161. 
Grossman, L. and Larimer, J. (1974), Rev. Geophys. Space Phys. 12, $71-101$.

Grossman, I. '(1975), Goechim. Cosmochim. Acta 39, 433-454.

Gubbins, D. (1976), Geophys. J. 47, 19-39.

Haddon, R, and Cleary, J.' (1974), Phys. Earth Planet. Int. 8, 211.

Hal1, H. and Murthy, V. (1971), Earth Planet. Sci. Letters 11, 239.

Hanks, T. and Anderson, D. (1969), Phys. Earth Planet. Interiors 2, 19.

Hide, R. and Mason, P. (1975), in: Advances in Phys. Vol. 24,

(Acađemic Press, London), 47-100.

Holton, J. (1972), An Introduction to Dynamic Meteorology (Academic Press, New Yórk).

Husebye, E., King, D. and Haddon, R. (1976), J. Geophys. Res. 81, $1870-1882$

Jacobs, J. (1975), The Earth's Core (Academic Press, London).

Jeanloz, R. and Ahrens, T. (1977), abstract E๑S Trans. Am. Geophys. U. 58,1236 .

Jones, "̈. (1977), J. Geophys. Res. 82, 1703-1709.

Jordan; T. and Anderson, D. (1974), Geophys. J. 36, 411.

Julian, B. and Sengupta, M. (1973), Nature 242, 443.

Kahle, A., Ball, R. and Vestine, E. (1967), J. Geophys. Res. 72, 4917.

Kennedy, G: and Higgins; G. (1973), The Moon 7,.. 14-21.

Kerridge, J. and Vedder, J. (1972); Science 177, 161.

Knopoff, L. and MacDonald, G. J. F. (1960), Geophys. J. 3, 68-77.

Lamb, H. (1932), Hydrodynamics, $6^{\text {th }}$ ed. (Dover, New York).

Landau, I. and Lifshitz, E. (1959), Fluid Mechanics (Pergamon Press, London).

Larimer, J. (1967), Geochim. Cosmochim. Acta 31, 1215-1238.

Larimer, J. and 'Anders, E. (1967), Geochim. Cosmochim. Acta 31, $1239-1270$ 
Lee, T., Papanastassịou, D: and Wasserburg, G. (1977), Astrophys. J. 211, $107-110$.

Levy, E. (1972), Astrophys. J. 171, 621.

Levy, E. (1972), Astrophys. J. 171, 635 .

Levy, E. (1976); An. Rev. Earth Planet. Sci. 4, 159-185.

Lewis, J. (1971), Earth P1anet. Sci. Letters 11 1, 130.

Liebermann, -R., Jones, L. and Ringwood, A.' (1977), Phys. Earth Planet.

Interiors $14,165-178$. $\therefore$

Loper, D. (1975), Phys. Earth P1anet. Interiors 11, 43-60.

Loper, 'D. and Roberts, P. (1977), abstract E丹S Trans. Am. Geophys. U. 58, 1 i29.

Loper, D. and Roberts, P. (1978), Geophys. Astrophys. Fluid Dynamics $\underline{9}$, $289-321$.

Mason, B. and Martin, P. (1977), Smith, Controb. Earth Sci. 19, 84-95.

Matsui, T. and Mizutani, H. (1977), Nature 270, 506-507.

McE1hinny, M. (1971), Science 172, 157 .

McElhinny, M., Briden, J., Jones, D. and Brock, A. (19̣68), Rẹ. Geophys. $6, \ddot{201}$.

McKenzie, D., Roberts, J. and Weiss, N. (1974), J. F1uid Mech. 62, 539-551.

Metchnik, V., Gladwin, M., and Stacey, F. (19674), J. Geomag. Geoelectr. 26, 405-415.

Moffatt, H. (1970), J.'Fluid Mech. 41, 435.

Moffatt, H. (1972), J. Fluid Mech. 53, 385 .

Moffatt, H. (1973), J. Fluid Mech. 57, 625 .

Mondt, J. (1977), Phys. Earth Planet. Int., 15, 46-59.

Morgan, W. (1971), Nature, 230, 42-43

Murthy, V. and H. Hal1 (1972), Phys. Earth Planet. Int., 6, 123-130. 
Neukem, G. (1968), PhD. Thesis, Univ.. of Heidelberg.

O'Keefe, J. and T. Ahrens (1976), Proc. Lunar Sci. Conf. 7th, 3007-3025.

Oversby, V. and A. Ringwood (1972), Earth Planet. Sci. Letters, 14, 345.

Parkër, E., (1955), Astrophys'. J., 122, 293.

Parker, E. (1969), Astrophys. J., 158, 815.

Parker, E., (1971), Astrophys. J., 164, 491.

Peltier, W., W. Farrell and J. Clark (1978), in press.

Phillips, i. (1963), Rev. Geophys., 1, 123.

Phillips, J. (1977), J. Geophys. Res., 82, 835 .

Phillips, J. and A. Cox (1976), Geophys. J., 45, 19-33.

Phinney, R. and L. Cathles (1969), J. Geophys. Res., 74, 1556-1574.

Reid, A. (1972), Ph.D. Thesis, Univ, of Alberta.

Rikitake, T. (1967), J. Geomagn. Geoelect. 19, 129.

Ringwood, A. (1966), in: P. Hurley ed., Advances in Earth Science,

(M.I.T. Press, Cambridge, Mass.).

Ringwood, A. (i972), in: E. Robertson ed., The Nature of the Solid

Earth (McGraw-Hi11, New York).

Ringwood, A. (1975), Composition and Petrology of the Earth's Mantle,

(McGraw-Hi11, New York).

Ringwood, A. (1977), Austr. Nat. U. Publ., No. 1277.

Roberts, G. O. (1972), Phil. Trans. R. Soc., A271, 411.

Roberts, P. H. (1971), in: 'A. Zmuda ed., World Magnetic Survey 1957-1969,

IAGA Bul1. 28, (IUGG Pub1. Off., Paris).

Roberts, P. H. and S. Scott (1965), J. Geomagn. Geoelect., 17, 137.

Roberts, P. H. and M. Stix (1971), transl. of papers by F. Krause,

K. Radler and M. Steenbeck, NCAR Tech. note IA-60, (BouIder, Colorado). Rochester, M., J. Jacobs, D. Smylie and K. Chong (1975), Geophys. J. $\underline{43}, 661-678$. 


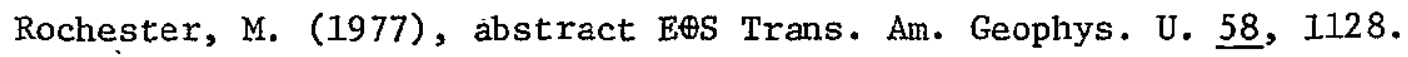
Ross, J. and L. Aller. (1976), Science, 191; 1223-1229. Sacks, I. and Beach, L. (1974), Carnegie Inst. Wash. Year Book 73, $1020-1032$.

Seitz, M. and I. Kushiro (1974), Science, 183, 954.

Shirck, J. (1974), Earth Planet. Sci. Letters, 23, 308.

Stewart, A. and E. Irving (1973), Trans. Am. Geophys. Un., 54, 248.

Strong, H. (i959), J. Geophys. Res., 64, 653.

Tozer, D. (1972), Phys. Earth Planet. Int., 6, ' l'82.

Turekian, K. and S. Clark (1969), Earth Planet. Sci. Letters, $\underline{6}$, 346-348

Urey, H. (1952), The Planets (Yale University Press).

Urey, H. (1955), Proc. Nat. Acad. Sci. U. S., 41, 127.

Usselman, T. (1975), Am. J. Sci., 275, 291-303.

Verhoogen, J. (1961), Geophys. J., 4 278.

Verhoogen, J. (1973), Phys. Earth Planet. Int., 1, 47-58.

Wänke, H., H. Bàddenhausen', H. Palme and B. Spettel (1974), Earth Planet. Sci. Letters, 23, 1-7.

Wright, C.. and Lyons, J. (1975), Geophys. J. 40, '115-138.

Wyllie, P. (1971), The Dynamic Earth, (J. Wiley \& Sons, New York).

Yukutake, T. (1970), Comments Earth Sci. Geophys., 1, 55 . 
TABLE 1

Abundances of fully accreted $\mathrm{Ca}, \mathrm{Al}$ and accreted mass of oxides calculated with Fe core $\sim 1.7 \times 10^{27} \mathrm{gms}$

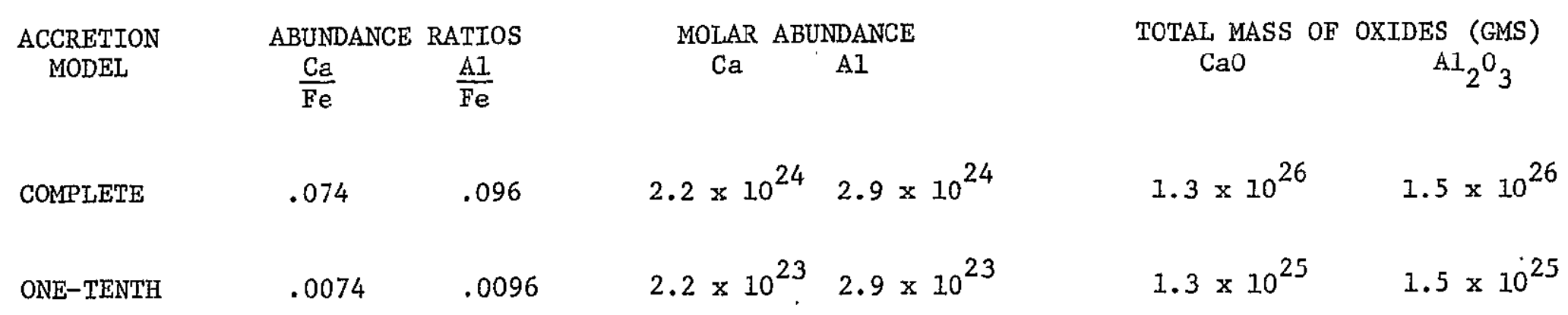


TABLE 2

Calculated condensate compositions compared with the compositions of Allende Type A inclusions. Also shown is the model composition which is the mean value of the inclusion compositions. (After Grossman, 1975)

\begin{tabular}{|c|c|c|c|c|c|}
\hline OXIDE & $\begin{array}{l}\text { TYPE A } \\
\text { (i) }\end{array}$ & $\begin{array}{l}\text { INCLUSION* } \\
\text { (ii) }\end{array}$ & $\begin{array}{l}\text { CALCULA } \\
\text { Composi } \\
1.500^{\circ} \mathrm{K}\end{array}$ & $\begin{array}{l}\text { ENSATE } \\
P_{\text {tot }}=10^{-3} \text { atm. } \\
\quad 1475^{\circ} \mathrm{K}\end{array}$ & $\begin{array}{l}\text { MODEL } \\
\text { COMPOSITION }\end{array}$ \\
\hline $\mathrm{CaO}$ & 29.7 & 36.5 & 35.7 & 32.3 & 33 \\
\hline $\mathrm{Al}_{2} \mathrm{O}_{3}$ & 41.8 & 35.1 & 38.8 & 34.8 & 38 \\
\hline $\mathrm{SiO}_{2}$ & 18.0 & $22.2^{\circ}$ & 19.3 & 21.7 & 20 \\
\hline MgO & 9.7 & 5.4 & 4.3 & 9.4 & 8 \\
\hline $\mathrm{TiO}_{2}$ & 0.84 & 0.79 & 2.0 & 1.8 & 0.8 \\
\hline
\end{tabular}

* (i) and (ii) are the compositions corresponding to the extremes of the spinel/melilite ratio. 
TABLE 3

Model composition of refractory material and calculated total mass TYPE A INCLUSIONS TOTAL MASS OF REFRACTORIES (GMS)

\begin{tabular}{lcccc} 
OXIDE & wt. $\%$ & $\frac{\text { 韭O1es }}{100 \mathrm{gm}}$ & COMPLETE & ONE-TENTH \\
\hline $\mathrm{CaO}$ & 33 & .59 & $3.8 \times 10^{29}$ & $3.8 \times 10^{25}$ \\
$\mathrm{Al}_{2} \mathrm{O}_{3}$ & 38 & .37 & $3.9 \times 10^{26}$ & $3.9 \times 10^{25}$ \\
$\mathrm{TiO}_{2}$ & 0.8 & .01 & & \\
$\mathrm{MgO}$ & 8 & .20 & & \\
$\mathrm{SiO}_{2}$ & 20 & .33 &
\end{tabular}


TABLE $\quad 4$

Heat production of $\mathrm{U}$ and. Th contained in refractory material

\begin{tabular}{|c|c|c|c|c|c|}
\hline \multirow[t]{2}{*}{ Element } & \multirow[t]{2}{*}{ Concentration (ppb) } & \multicolumn{2}{|c|}{ MASS (gms) } & \multicolumn{2}{|c|}{$\begin{array}{l}\text { TOTAL HEAT PRODUCTION } \\
\mathrm{ergs} / \mathrm{sec}\end{array}$} \\
\hline & & COMPLETE & ONE-TENTH & COMPLETE & ONE-TENTH \\
\hline $\mathrm{U}$ & 163 & $6.3 \times 10^{19}$ & $6.3 \times 10^{18}$ & $\sim 10^{20}$ & $v 10^{19}$ \\
\hline Th & 635 & $2.4 \times 10^{20}$ & $2.4 \times 10^{19}$ & & \\
\hline
\end{tabular}


TABLE 5

Physical properties for the fluid core

\begin{tabular}{|c|c|c|c|}
\hline PROPERTY & SYMBOL & VALUE & SOURCE \\
\hline Density & $\rho$ & $v 10 \mathrm{gm} \mathrm{cm}^{-3}$ & e.g. Jordan \& Anderson 1974 \\
\hline Gravity & $g$ & $\sim 10^{3} \mathrm{~cm} \mathrm{sec}-2$ & $n$ \\
\hline $\begin{array}{l}\text { Thermometric } \\
\text { conduction }\end{array}$ & $K$ & $\sim 10^{-1} \mathrm{~cm}^{2} \mathrm{sec}^{-1}$ & e.g. Kennedy \& Higgins 1972 \\
\hline Heät capacity & Cp & $\sim 5 \times 10^{6} \mathrm{erg}^{-1} \mathrm{gm}^{-1} \mathrm{deg}^{-1}$ & Verhoogen 1961 \\
\hline Heat of Fusion & $\mathrm{H}$ & $\sim 4 \times 10^{9} \mathrm{erg}^{-1}$ & $"$ \\
\hline $\begin{array}{l}\text { Coefficient of } \\
\text { volume expansion }\end{array}$ & $\alpha$ & $\sim 5 \times 10^{-6} \mathrm{deg}^{-1}$ & Frazer 1973 \\
\hline Kinematic viscosity & $v$ & v1 $\mathrm{cm}^{2} \mathrm{sec}^{-1}$ & See Gibbins 1976 \\
\hline Coriolis parameter & f & $210^{-4} \mathrm{sec}^{-1}$ & (mid-latitudes) \\
\hline $\begin{array}{l}\text { Heat flux at } c-m-b \\
\quad \text { from refractories }\end{array}$ & $\mathrm{F}$ & v10 erg $\mathrm{cm}^{2} \mathrm{sec}^{-1}$ & $\begin{array}{l}\text { Heat production at } 1 / 10 \\
\text { of } c-m-b \text { surface }\end{array}$ \\
\hline
\end{tabular}


TABLE 6

Heat production of short lived nuclides

Concentration

Nuclide

$1 / 2$ 1ife

Energy

erg/gm(nuclide)

in refractories

$\begin{array}{lll}{ }^{244} \mathrm{Pu} & 76 \mathrm{~m} \cdot \mathrm{y} \cdot . & 6.24 \times 10^{16} \\ { }^{236} \mathrm{U} & 24 \mathrm{~m} \cdot \mathrm{y} \cdot & 1.86 \times 10^{16} \\ { }^{26} \mathrm{~A} 1 & 0.72 \mathrm{~m} \cdot \mathrm{y} \cdot & 2.4 \times 10^{17}\end{array}$

$0.67 \mathrm{ppb}$

$16.3 \mathrm{ppb}$

$5 \times 10^{-6}$
Total

Heat Production for Average Refractory Mode1 ( $2 \times 10^{26} \mathrm{gms}$ )

ergs

$8.4 \times 10^{33}$

$6.1 \times 10^{33}$

$2 \times 10^{38}$ 


\section{TABLE 7}

Mineral densities determined at a pressure of $1.2 \mathrm{Mbar}$

\begin{tabular}{|c|c|c|c|c|}
\hline $\begin{array}{l}\text { Oxides and } \\
\text { Minerals }\end{array}$ & $\left(\begin{array}{l}\mathrm{g} \mathrm{cm}^{-3}\end{array}\right)$ & $\left(\begin{array}{c}\mathrm{M} \\
\mathrm{g} / \mathrm{mol})\end{array}\right.$ & $\begin{array}{r}\text { Molar } \\
\text { volume } \\
\left(\mathrm{cm}^{3}\right)\end{array}$ & Reference \\
\hline & & & $\cdot$ &. \\
\hline $\mathrm{SiO}_{2}$ & $5.14 \pm 0: 1$ & 60.1 & 11.20 & $\begin{array}{r}\text { Ahrens et al. } \\
\text { (1977) }\end{array}$ \\
\hline 2 (mg: $\left.45^{\mathrm{Fe}}{ }_{.55}\right)^{\mathrm{SiO}_{4}}$ & $6.11 \pm 0.1$ & 175.4 & 28.7 & $"$ \\
\hline $2\left(\mathrm{Mg}_{.9} \mathrm{Fe} .1\right)^{\mathrm{SiO}_{4}}$ & $5.27 \pm 0.1$ & 147.0 & 27.9 & $"$. \\
\hline$\left(\mathrm{Mg}_{.9} \mathrm{Fe} .{ }_{.1}\right) \mathrm{SiO}_{3}$ & $5.30 \pm 0.1$ & 103.6 & 19.6 & $"$ \\
\hline CaO & $5.71 \pm 0.1$ & 56.1 & 9.8. & $\begin{array}{c}\text { JeanIoz \& Ahrens } \\
(1977)\end{array}$ \\
\hline $\mathrm{Al}_{2} \mathrm{O}_{3}$ & $5.18 \pm 0.1$ & 102.0 & 19.7 & Clark (1966) \\
\hline $\mathrm{TiO}_{2}$ & $6.60 \pm 0.1$ & 79.9 & $12: 1$ & $\begin{array}{r}\text { Ahrens et al. } \\
\text { (1977) }\end{array}$ \\
\hline
\end{tabular}


TABLE 8

Contrast in composition of normal mantle and refractory material

\begin{tabular}{|c|c|c|c|c|}
\hline \multirow[t]{2}{*}{ Oxides } & \multicolumn{2}{|c|}{ Normal Mantle } & \multicolumn{2}{|c|}{ Refractories } \\
\hline & wt. \% & \#moles/100 gms. & wt. $\%$ & Hholes/100gms. \\
\hline $\mathrm{SiO}_{2}$ & 45.2 & .773 & 20.0 & .33 \\
\hline MgO & 37.5 & .964 & 8.0 & .20 \\
\hline FeO & $8.00^{\circ}$ & .114 & $(1.44)$ & $(.02)$ \\
\hline $\mathrm{CaO}$ & 3.10 & .057 & 33.0 & $.59 \cdot$ \\
\hline $\mathrm{AI}_{2} \mathrm{O}_{3}$ & 3.50 & .035 & 38.0 & .37 \\
\hline $\mathrm{TiO}_{2}$ & .0 .70 & .009 & 0.80 & .01 \\
\hline
\end{tabular}


Calculated composite densities for the model compositions (Fo $\rightarrow$ Forsterite, En $\rightarrow$ Enstatite)

Mode1

Norma1 $\begin{gathered}\text { olivine } \\ \text { rich } \\ \text { Pyroxene } \\ \text { rich }\end{gathered}$

\section{Composition}

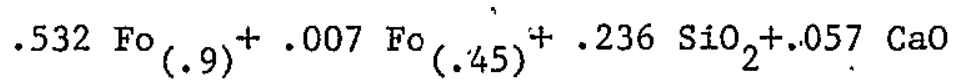

$+.035 \mathrm{Al}_{2} \mathrm{O}_{3}+.009 \mathrm{TiO}_{2}$

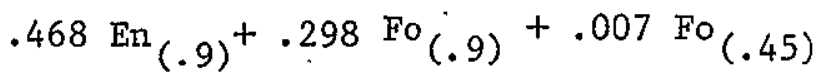

$+.057 \mathrm{CaO}+.035 \mathrm{AI}_{2} \mathrm{O}_{3}+.009 \mathrm{TiO}_{2}$
$.11 \mathrm{Fo}(.9)+.22 \mathrm{SiO}_{2}+.59 . \mathrm{CaO}$

$+.37 \dot{\mathrm{Al}}_{2} \mathrm{O}_{3}+.01 \mathrm{TiO}$

$.22 \mathrm{En}(.9)^{+} .11 \mathrm{SiO}_{2}+. .59 \mathrm{CaO}$

$$
+.37 \mathrm{Al}_{2} \mathrm{O}_{3}+.01 \mathrm{TiO}_{2}
$$

Composite Dȩnsity (gm $\mathrm{cm}^{-3}$ )

$5.28 \pm .1$

$5.31 \pm .1$

$5.36 \pm: 1$

$5.38 \pm .1$ 
TABLE 10

Seismic parameter $\Phi_{0}^{-}$of the component oxides

\begin{tabular}{|c|c|c|c|c|c|c|}
\hline Oxides & & $\Phi_{0}(\mathrm{~km} / \mathrm{sec})^{2}$ & & Referenc & & \\
\hline $\mathrm{SiO}_{2}$ & & 85 & Anderson & (1969), & Davies & (1974) \\
\hline & . & . & ' & & & \\
\hline MgO & & 45 & $"$ & , & " & \\
\hline Feo & & 27,30 & . & , & " & \\
\hline $\mathrm{CaO}$ & & 32,35 & $"$ & , & " & \\
\hline $\mathrm{Al}_{2} \stackrel{\mathrm{O}}{ }_{2}$ & & 64. & $"$ & , & $\cdot$ & \\
\hline $\mathrm{TiO}_{2}$ & & 50 & Davies, & $\begin{array}{c}\text { (1974) } \\
.\end{array}$ & . & \\
\hline $\mathrm{MgSiO}_{3}$ & perovskites & 62 & Liẹberma & an et al. & $\cdot(1977)$ & \\
\hline $\mathrm{CaSiO}_{3}$ & & 52 & $-" 1$ & & & \\
\hline
\end{tabular}


Figure 1: $\quad$ Physical properties of the core and lowermost mantle; density; pressure, shear and compressional wave velocities. (After Jordan and Anderson 1974).

Figure 2: $\quad$ Condénsation sequence from the solar nebula at total préssure $=10^{-3}$ atm. The heavy metals and $\mathrm{Ca}$, A1 silicates condense before $\mathrm{Fe}$. Olivine $\left(\mathrm{Mg}_{2} \mathrm{SiO}_{4}\right)$ begins condensation before all of the $\mathrm{Fe}$ is condensed (after Grossman and Larimer-1974)

Figure 3: $\quad$ Geometry and simplified density structure of initial and final configurations by conserving mass and radius. The initial core geometry from pure inhomogeneous accretion with the assumed density structure is shown in (a), (b) shows the average density structure for "distributed" geometry, and (c) shows the final geometry after the core segregation event with the refractory silicates distributed irregularly in the lowermost mantle: (The near equivalence of refractory and normal mantle density is demonstrated in 2.6).

Figure 4: Temperatures relevant to the core's early thermal history. A lower bound on the initial.temperature is taken from the condensation temperature of mantle silicates. The range indicates the temperature increase from adiabatic compression. A range of melting temperatures is shown to indicate the uncertainties involved in determining how much heating of the core is needed to commence melting. 

indicates the possible values of the adiabatic gradient. The two gradients for internal heating, are calculated for half and one-tenth of the accreted $U$ and Th dispersed within the core. "The gradient due to. freezing of the inner core assumes the entire inner core has frozen over the age of the Earth. Neither freezing of the inner core nor internal heating from $U$ and. Th seem capảble of maintaining an adiabatic gradient throughọut. The gradient caused by cooling from the mantlè at a time scale $\ll \dot{1}$ b.y. is also shown though of dublous importance:

Figure. 6: If the lighter element forms a eutectic system with $\mathrm{Fe}$, then the fluid composition will vary with radius and. temperature, as indicated by the contours of lighter element percentage. The hatched region shows-the range of core adiabats. Dependent upon the temperature gradient, the core could be compositionally stratified: " For example, with the particular core adiabat shown -above; the fluid would contain $7 \%$ lighter element at the inner core and $14 \%$ at the core-mantle boundary.

Figure 7: The geometry of heating and cooling of the core by refractory material. Though there are lateral variations at smaller scales, the largest length scale of $1,000 \mathrm{~km}$. is the most important for fluid motions. 
The fluid flow within a rotating annulus viewed from above.

Thị is analogous to looking down on an individual refractory heat source from above. The flow in (a) is azimuthally symmetric. By either increasing rotation or decreasing the Brunt frequency with constant length scales, baroclinic instabilities will appear as azimuthal waves shown in (b). Decreasing. the length scale of the waves wili eventualiy give rise to the irregular regime of fluid flow as in (c). 


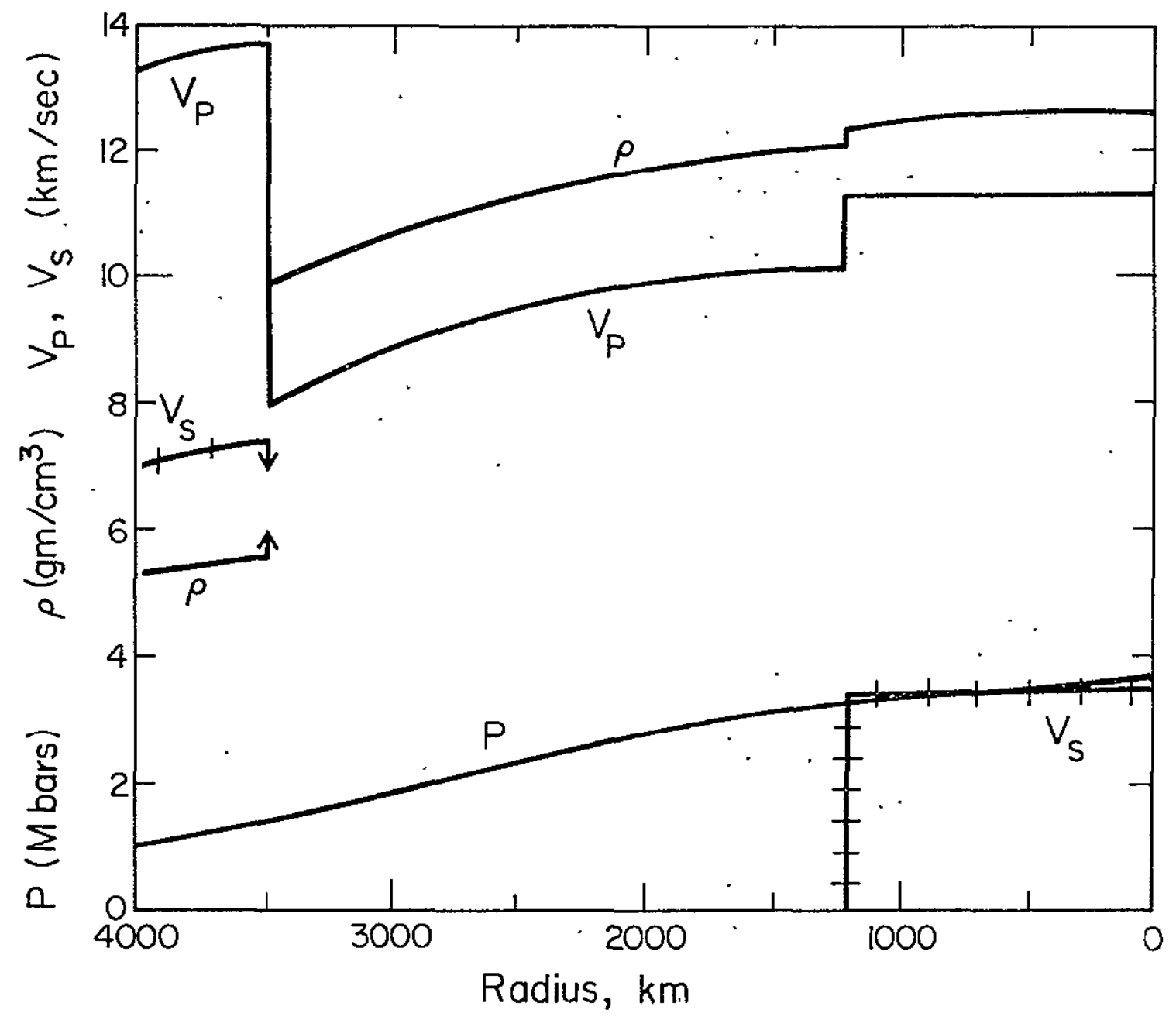

Fig. 1 


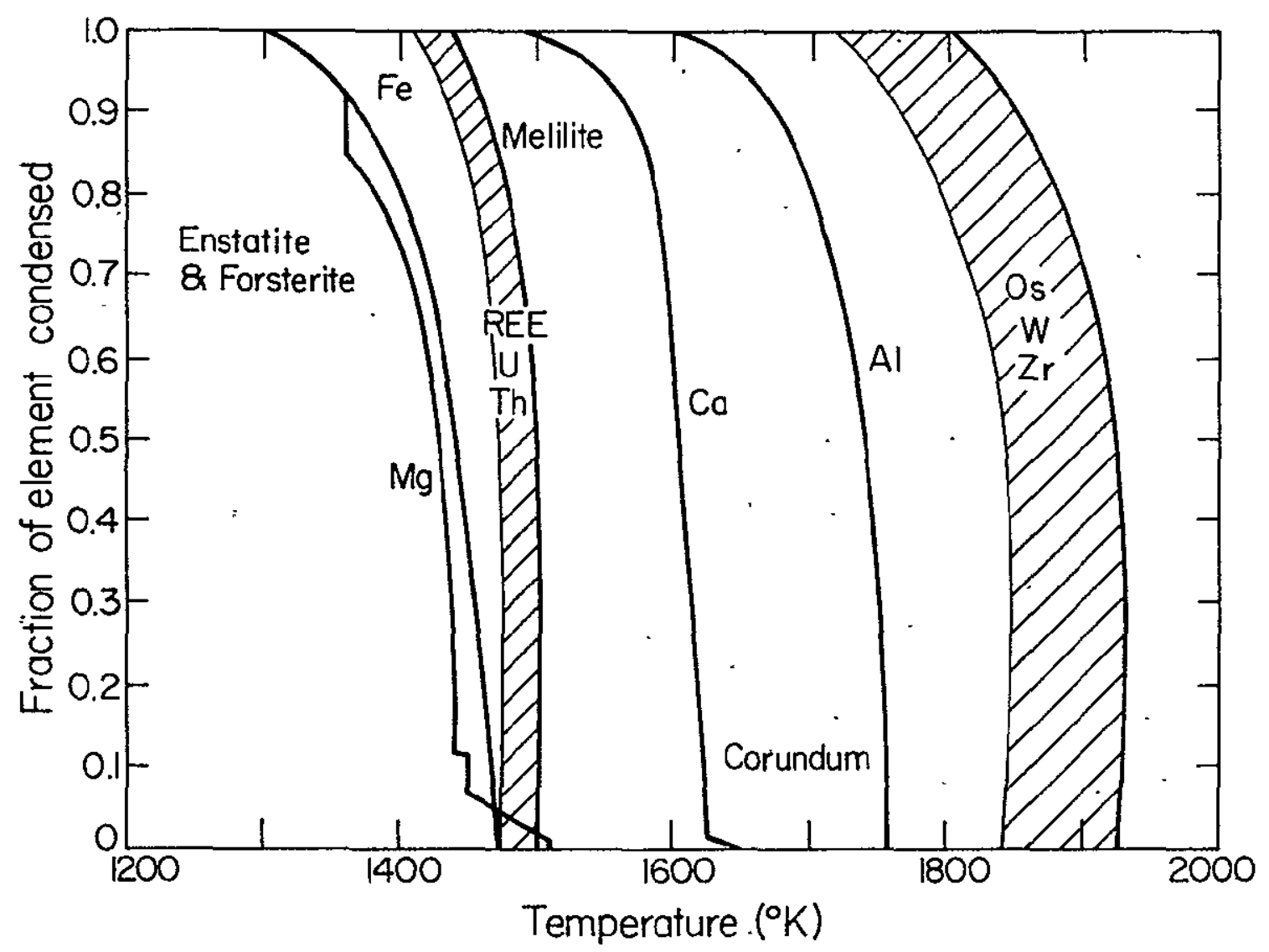

Fig. 2 

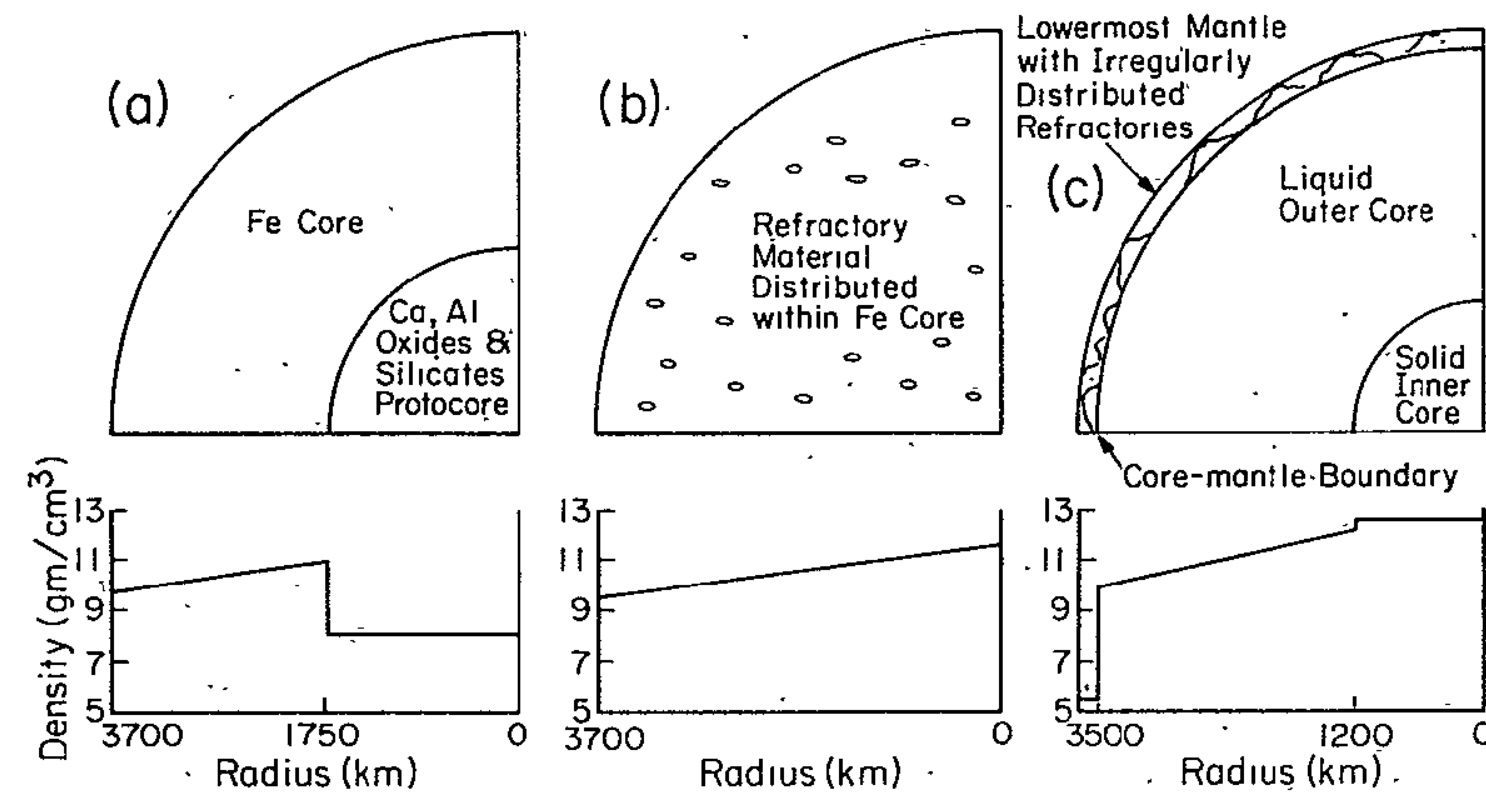

(a)Pure Inhomogeneous Accretion (b) Distributed Accretıon

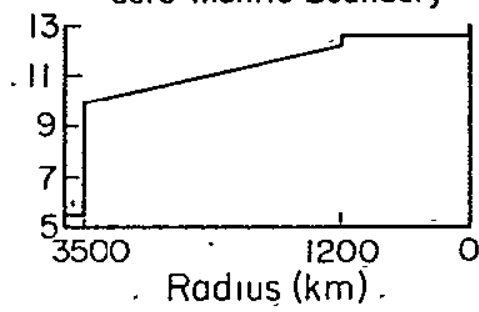

(c) Final (present) Configuration

Fig. 3 


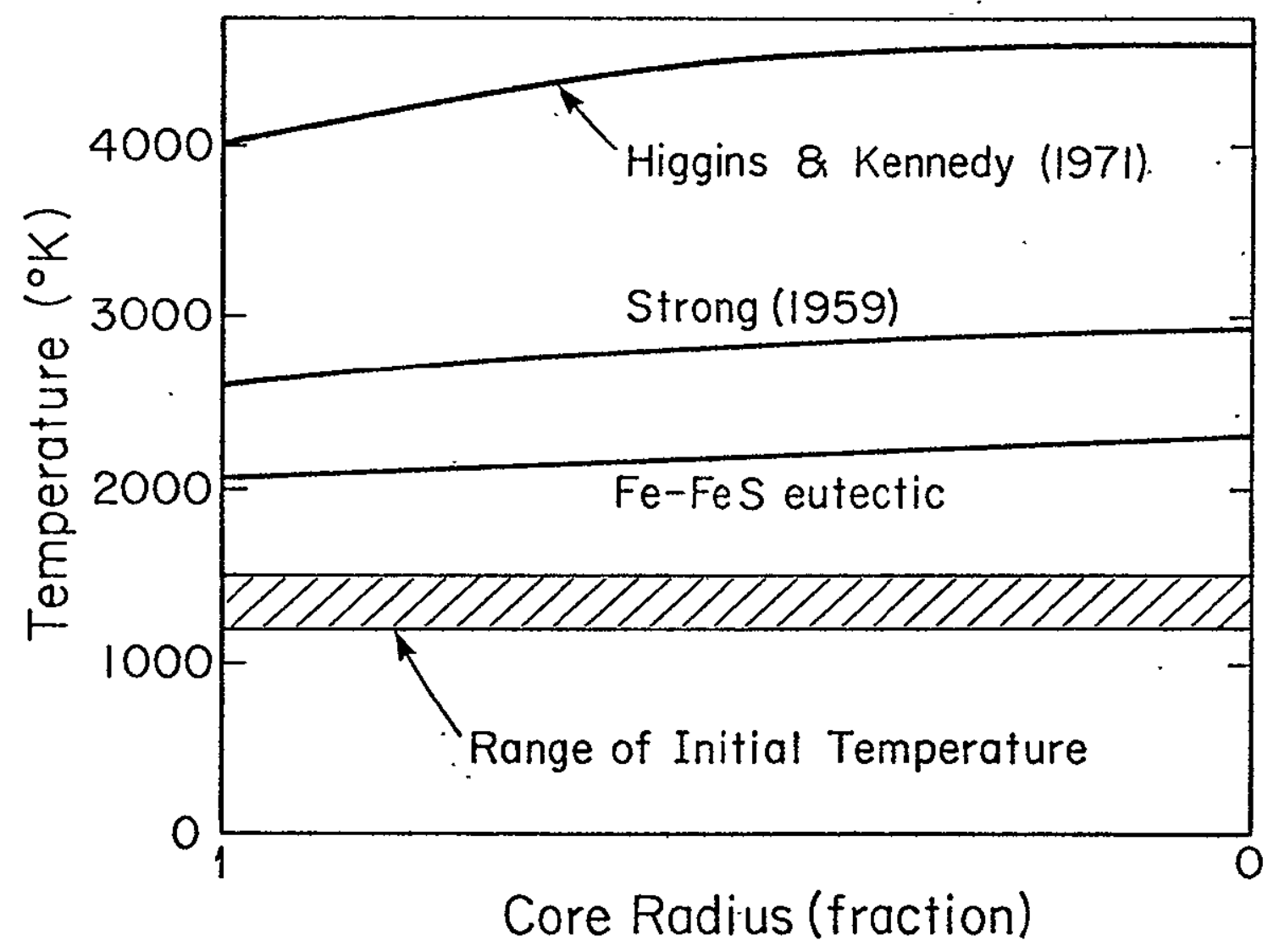

Fig. 4 
- K⿸广 OE POOR OUALITY

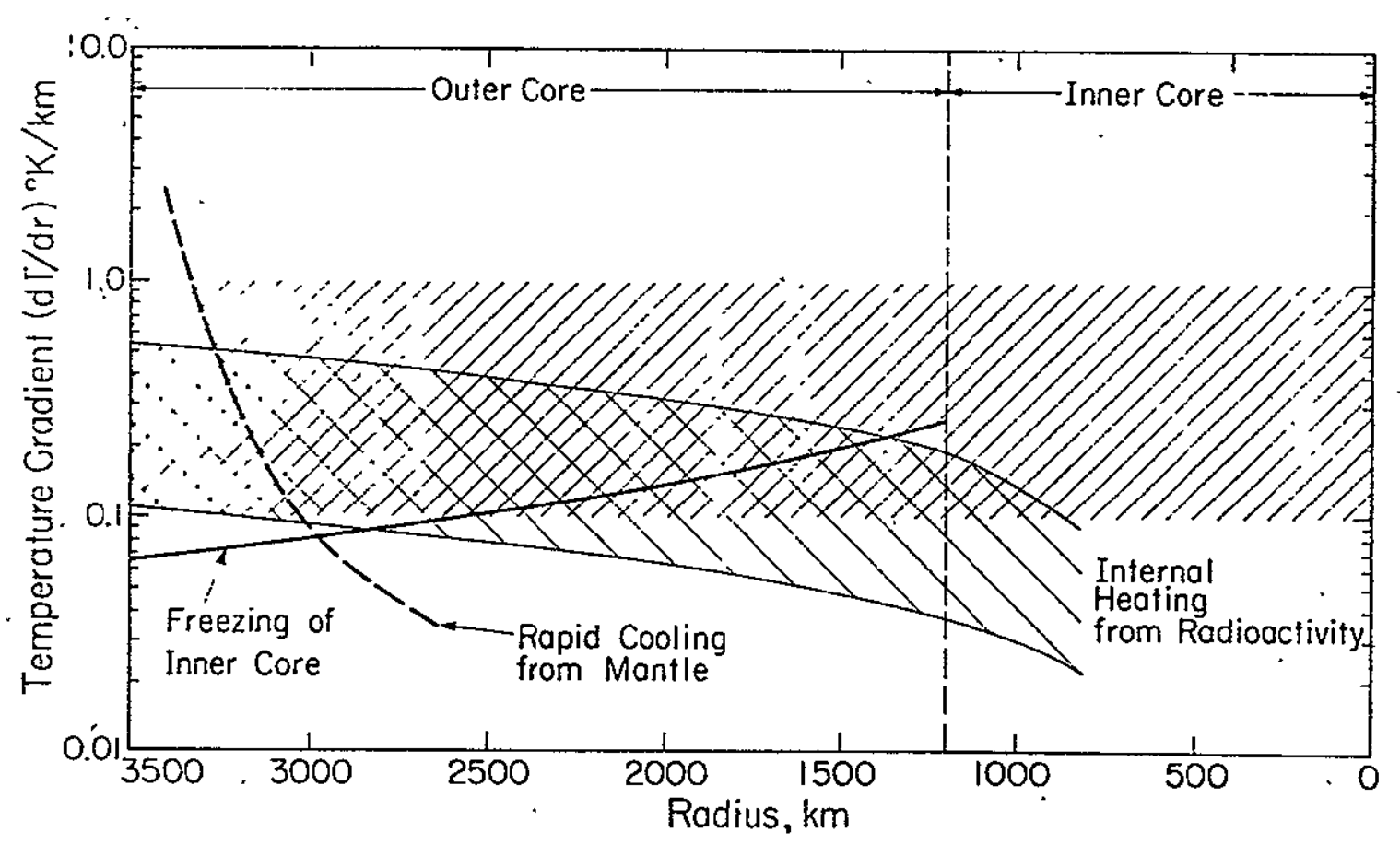

Fig. 5 


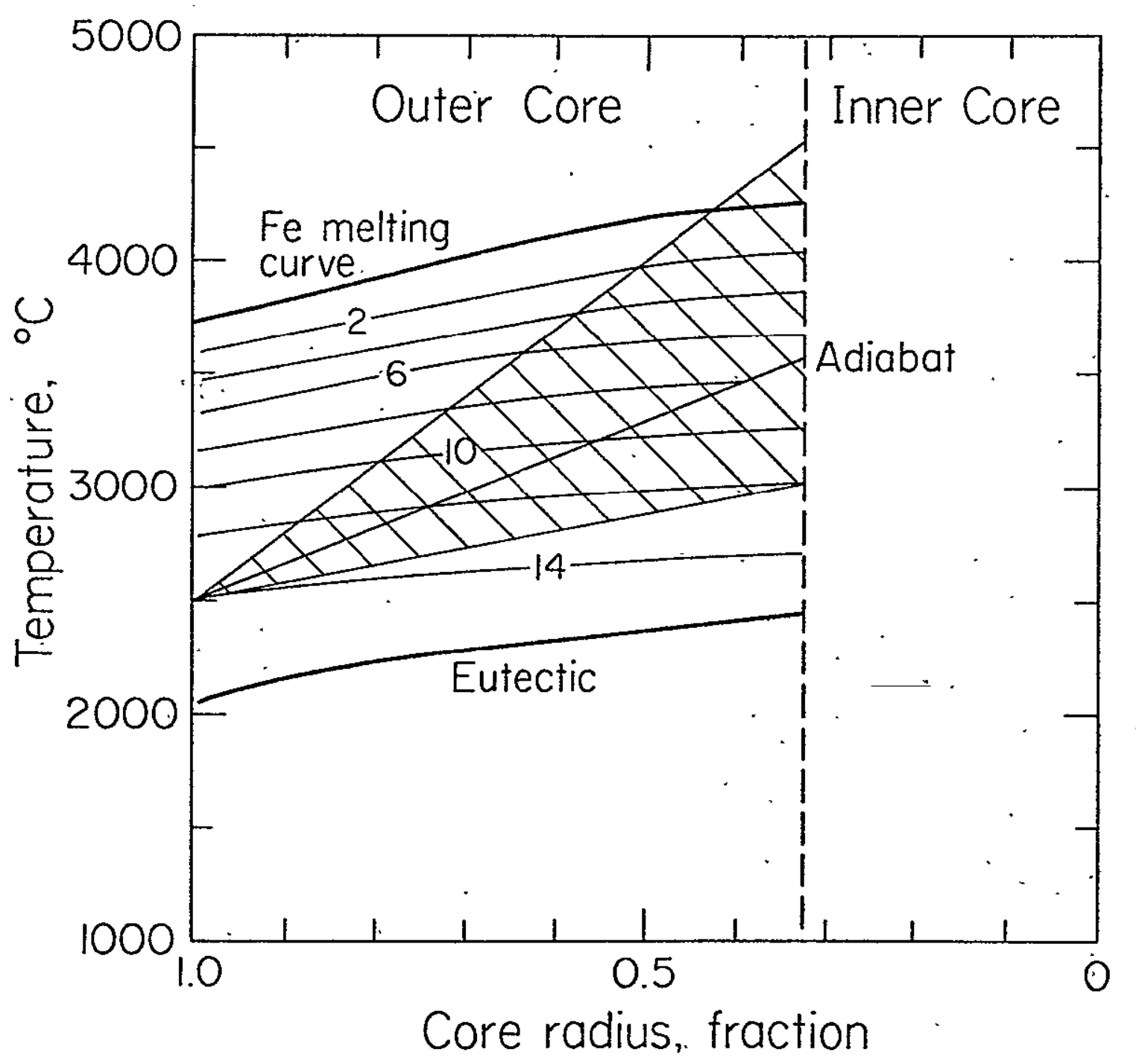

Fig. 6 


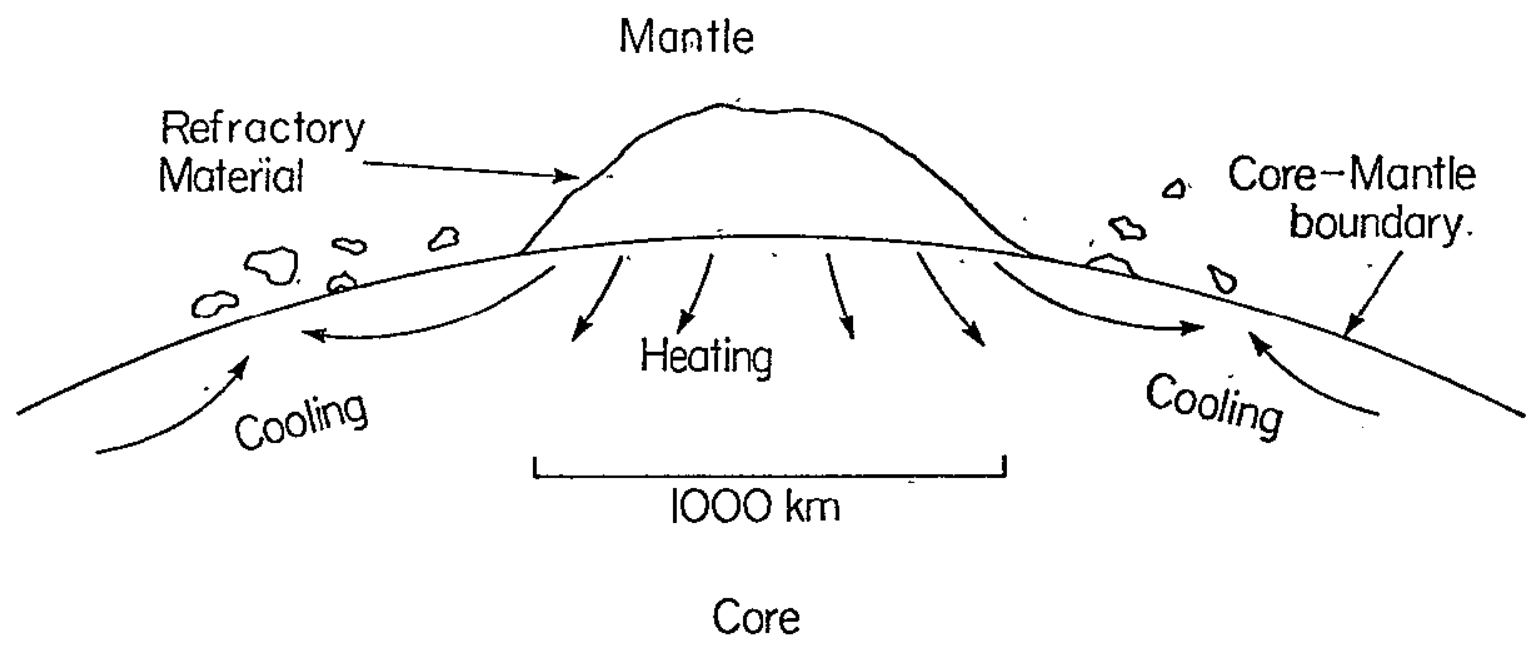

Fig. 7 


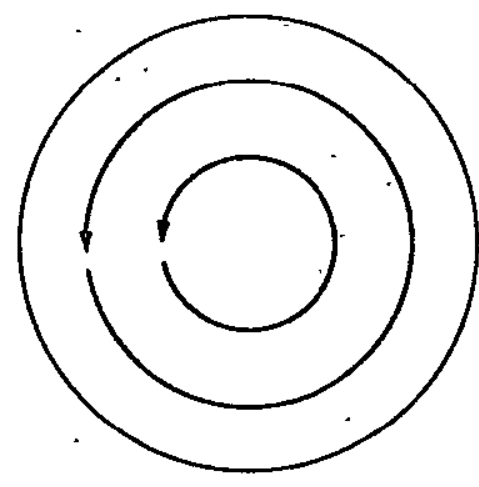

(a)

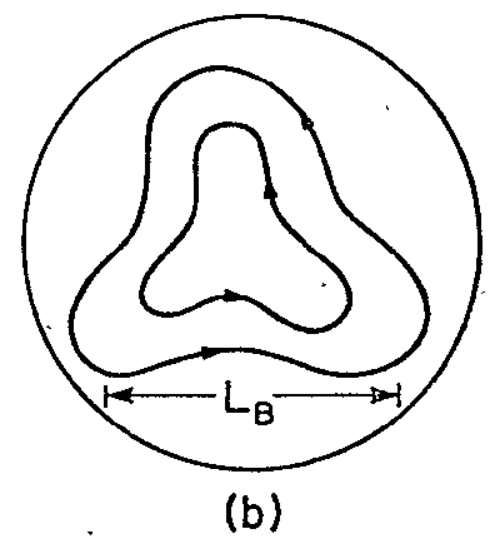

Wave-like Instabilities

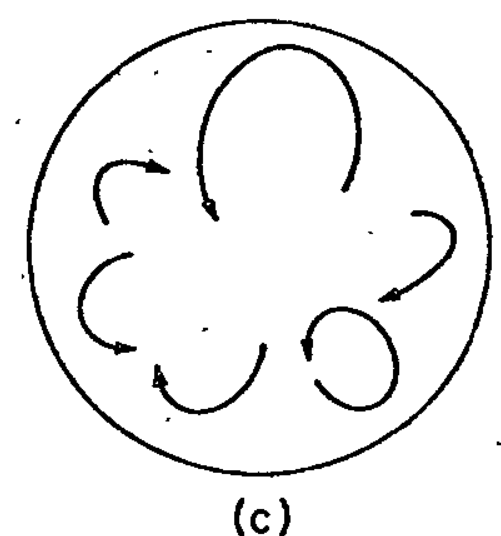

Smaller Scale Eddies

\section{Symmetric Regime}

